\title{
Time preferences, study effort, and academic performance
}

Citation for published version (APA):

Non, J. A., \& Tempelaar, D. T. (2014). Time preferences, study effort, and academic performance. Maastricht University, Graduate School of Business and Economics. GSBE Research Memoranda No. $012 \mathrm{https}: / /$ doi.org/10.26481/umagsb.2014012

Document status and date:

Published: 01/01/2014

DOI:

10.26481/umagsb.2014012

Document Version:

Publisher's PDF, also known as Version of record

\section{Please check the document version of this publication:}

- A submitted manuscript is the version of the article upon submission and before peer-review. There can be important differences between the submitted version and the official published version of record.

People interested in the research are advised to contact the author for the final version of the publication, or visit the DOI to the publisher's website.

- The final author version and the galley proof are versions of the publication after peer review.

- The final published version features the final layout of the paper including the volume, issue and page numbers.

Link to publication

\footnotetext{
General rights rights.

- You may freely distribute the URL identifying the publication in the public portal. please follow below link for the End User Agreement:

www.umlib.nl/taverne-license

Take down policy

If you believe that this document breaches copyright please contact us at:

repository@maastrichtuniversity.nl

providing details and we will investigate your claim.
}

Copyright and moral rights for the publications made accessible in the public portal are retained by the authors and/or other copyright owners and it is a condition of accessing publications that users recognise and abide by the legal requirements associated with these

- Users may download and print one copy of any publication from the public portal for the purpose of private study or research.

- You may not further distribute the material or use it for any profit-making activity or commercial gain

If the publication is distributed under the terms of Article $25 \mathrm{fa}$ of the Dutch Copyright Act, indicated by the "Taverne" license above, 


\section{Maastricht University}

Arjan Non, Dirk Tempelaar

Time Preferences, Study Effort, and Academic Performance

RM/14/012

\section{GSBE}

Maastricht University School of Business and Economics

Graduate School of Business and Economics

P.O Box 616

NL- 6200 MD Maastricht

The Netherlands 


\title{
Time Preferences, Study Effort, and Academic Performance*
}

\author{
Arjan Non Dirk Tempelaar $^{\ddagger}$
}

March 2014

\begin{abstract}
We analyze the relation between time preferences, study effort, and academic performance among first-year Business and Economics students. Time preferences are measured by stated preferences for an immediate payment over larger delayed payments. Data on study efforts are derived from an electronic learning environment, which records the amount of time students are logged in and the fraction of exercises completed. Our third measure of study effort is participation in an on-line summer course. We find that impatient students show weaker performance, but the consequences are relatively mild. Impatient students obtain lower grades and fail first sit exams more often, but they do not obtain significantly fewer study credits, nor are they more likely to drop out as a result of obtaining fewer study credits than required. We find a weak negative relationship between impatience and study effort. Differences in study effort therefore cannot explain impatient students' lower academic performance.
\end{abstract}

JEL-Codes: D03, D90, I21

Keywords: Time preferences; Education; Study effort, Academic performance.

\footnotetext{
${ }^{*}$ We thank seminar participants in Maastricht and Trier. We are particularly grateful to Mark Bernard for valuable help in the data collection and many useful suggestions. We also thank Bart Golsteyn, Bert van Landeghem, and Ulf Zölitz for helpful comments.

${ }^{\dagger}$ Corresponding author: Maastricht University, Research Centre for Education and the Labor Market (ROA), and CESifo. E-mail: j.non@maastrichtuniversity.nl. Postal adress: ROA, P.O. Box 616, 6200 MD Maastricht, The Netherlands.

${ }^{\ddagger}$ Maastricht University, School of Business and Economics. Email: d.tempelaar@maastrichtuniversity.nl
} 


\section{Introduction}

People are often confronted with the choice to take a costly action now in order to obtain a benefit in the future. Although people generally tend to attach less weight to future outcomes than to present outcomes, there is substantial heterogeneity in how individuals behave in those kind of situations. It has been found that experimental measures of individuals' time preferences correlate with their alcohol consumption, smoking behaviour, body mass index (Borghans and Golsteyn, 2006; Chabris et al., 2008; Sutter et al., 2013), and credit card borrowing (Meier and Sprenger, 2010). Differences in individuals' time preferences may also help to explain the extent to which individuals are successful in education. Ultimately, being successful in education requires putting in effort. Individuals' choice of effort typically involves an intertemporal trade-off: effort costs of studying an additional hour are incurred immediately, while the benefits materialize in the future. We would therefore expect that impatient individuals exert less effort, resulting in lower educational attainment and performance. ${ }^{1}$

A number of recent papers find evidence in line with this hypothesis. Kirby et al. (2005) find that, in a sample of undergraduate students of two American colleges, impatient students have significantly lower grade point averages. Cadena and Keys (2012), using panel data representative for the US population, show that individuals who are classified as impatient by their interviewer, are more likely to drop out from high school and from college. Golsteyn et al. (2014) link individuals' time preferences measured at age 13 with several outcomes in later life, up to 40 years later. They conclude that individuals who make impatient choices at age 13 obtain lower grade point averages in compulsory school and high school, and are less likely to graduate from both high school and university. De Paola and Gioia (2013) find that, in a sample of Italian university students, impatient students obtain lower grades, while they find no differences in the number of study credits earned three years after enrollment.

In this paper, we contribute to this literature by investigating the relation between time preferences, study effort, and academic performance. In contrast to previous studies, we explore data on actual study efforts rather than analyzing data on study outcomes only. We collect information on study efforts of 799 first-year Business and Economics students for an obligatory course in quantitative methods. An interesting feature of this course is that students are supposed to practice the course material in an electronic learning environment, which automatically records for each student the amount of time logged in, as well as the percentage of exercises solved without help of the electronic assistance tools. We use this information as

\footnotetext{
${ }^{1}$ For a more general discussion on the role of time discounting in human capital investment, see Becker (1962) and Ben-Porath (1967).
} 
our first two measures of study effort. A third measure of effort is voluntary participation in an on-line summer course that addresses deficiencies in basic mathematical skills. To investigate how impatience relates to first-year academic performance, we use four different performance measures: the average grade obtained in the first sit exams (i.e. excluding results obtained in re-examinations), the number of first sit exams failed, the number of study credits obtained during the first year, and whether students fulfill the university's requirements for first-year performance. The consequences of failing to meet those requirements are severe, namely exclusion from the study program. We measure time preferences by a survey question that confronts students with three hypothetical choices between an immediate payment of $€ 1000$ or a larger delayed payment, the respective amounts being $€ 1100$, $€ 1050$, and $€ 1250$.

By analyzing study efforts in addition to study outcomes, we provide more direct evidence on the existence of a causal relationship between time preferences and academic performance. Establishing causality is challenging if not impossible, as there is typically no exogenous variation in time preferences that can be exploited. A promising alternative strategy is therefore to investigate the channel underlying the relation between time preferences and academic performance, namely whether and to what extent impatient students actually exert less effort. This yields more direct evidence, which is important as study outcomes may be correlated with time preferences for other reasons than study effort. For instance, a consistent finding in the literature is that impatience is negatively correlated with measures of intelligence, see, in addition to the literature cited above, Frederick (2005), Shamosh and Gray (2008), Dohmen et al. (2010), and Castillo et al. (2011). As a result, to the extent that ability is unobserved or measured with error, the negative impact of impatience on educational attainment and performance may be overestimated. Although the estimated relation between impatience and study effort may also be prone to bias for the same reason, this possible bias most likely leads to underestimation of the effects, as we would expect that less able students study more hours. As another example, impatient students' weaker educational performance may be driven by ineffective learning habits, rather than by fewer actual study hours. For those and similar reasons, the cleanest way to test the hypothesis that impatient students exert less study effort, resulting in lower performance, is by employing direct measures of study effort.

We find that impatience is associated with weaker academic performance and less study effort, but the evidence is not unambiguous. Impatient students are less likely to complete almost all exercises provided by the electronic learning environment, but they are not significantly less likely to participate in the summer course, and we find no evidence that they study fewer hours. This seems hard to reconcile with some of our findings on the relation between time preferences and academic performance. Specifi- 
cally, we find that impatient individuals obtain lower grades, and fail a first sit exam more often. Students who always prefer the immediate payment are estimated to fail $28 \%$ more exams than other students, amounting to 0.5 additional failed exam per academic year. However, the effects become insignificant and ultimately disappear when the consequences of bad performance are more severe. Our point estimates suggest that impatient students are less likely to obtain all first year's study credits, but this effect is not statistically significant. Also, we find no evidence that impatient students are less likely to fulfill the university's performance requirements. So, we show that impatience has no severe immediate consequences, and that the differences in study effort between patient and impatient individuals are rather modest. Possibly, the effect on grades and failed first sit exams is somewhat overestimated, as we find a clear negative correlation between impatience and measures of ability, in line with existing studies.

Our findings suggest that impatient students make rational trade-offs: they accept lower grades and a higher probability of failing an exam, but they are not willing to accept substantial study delay, let alone being forced to abandon their studies as a result of insufficient performance. The consequences of impatience are therefore relatively modest. This is well in line with the results of De Paola and Gioia (2013), who find that impatience is reflected in lower grades, but not in higher dropout rates or fewer study credits. However, our result stands in remarkable contrast to the results of Cadena and Keys (2012) and Golsteyn et al. (2014), who find that impatience is associated with important life-lasting consequences, such as higher dropout rates and lower educational attainment. Moreover, Cadena and Keys (2012) report substantial evidence for dynamically inconsistent or impulsive behavior. A possible reason for those diverging findings is that Cadena and Keys (2012) and Golsteyn et al. (2014) investigate representative samples of the general population, whereas both De Paola and Gioia (2013) and we concentrate on university students. Arguably, time preferences have more dramatic effects on behavior in the general population, as more intelligent individuals, like university students, may have developed effective ways to curb impulsive tendencies, or may be better able to foresee the possible consequences of impatient behavior. ${ }^{2}$

We also analyze by means of a simple theoretical model, how the effects of impatience on study effort depend on ability and the functional form of the marginal benefits of effort. Based on this model, we repeat our analyses by ability, as measured by the score on a math entry test, but we find no clear differences between students of high and low ability. Moreover, we estimate the relation between time preferences and study effort for different levels

\footnotetext{
${ }^{2}$ Alternatively, the distribution of time preferences is much wider in the total population. However, Andersen et al. (2010) compare time preferences in a sample of university students with those in the general population, and find that the distributions do not differ that much.
} 
of understanding of the course material, as our theoretical model predicts that impatience is more relevant when students do not fully master the course material. Again, we find no differences. We also discuss several possible explanations for our finding that impatient students show weaker exam performance, while they do not seem to put significantly less effort into their studies. For instance, impatient students may study less effectively, or put in less effort in dimensions we cannot observe. The explanation that is most in line with the evidence is that the effect on grades is somewhat overestimated, as impatience is negatively correlated with ability, which is typically imperfectly measured. In our analyses we control for, among others, risk aversion, as risk attitudes may be related to time preferences (Anderhub et al., 2001; Dohmen et al., 2010; Andreoni and Sprenger, 2012; Sutter et al., 2013).

The paper proceeds as follows. First, we describe the background of our study and the data used in the analysis. Then, in section 3, we present the main analysis and results. Section 4 describes a simple theoretical model, and describes the results of the robustness checks we conduct on the basis of our theoretical framework. In section 5, we discuss possible interpretations of our results. Section 6 concludes.

\section{Data description}

\section{$2.1 \quad$ Background}

Our sample consists of all first-year students enrolled at the start of the academic year 2012-2013 at the School of Business and Economics of Maastricht University. We collected data on their study behaviour during an introductory course in quantitative methods, abbreviated as QM1. This course is obligatory for all students who are enrolled at the School of Business and Economics of Maastricht University and takes place the first period of the academic year. The course has a special place in the curriculum. Students enrolled at the School of Business and Economics are required to obtain at least 34 out of 60 course credits in their first year, and in addition pass at least one of the two courses in quantitative methods offered in the first year. Students who fail to meet those criteria receive a so-called 'negative binding study advice' (BSA), implying that they have to leave their study program, and are excluded from the study program for six years. ${ }^{3}$ Hence, students face strong incentives to pass this course.

The course consists of 7 weeks of lectures and tutorials, followed by a written exam. The aim of the course is to provide students with a basic understanding of mathematics and statistics. Attendance of lectures is not

\footnotetext{
${ }^{3}$ All universities in the Netherlands have similar regulations, although the exact performance requirements differ by university and department.
} 
obligatory. Tutorials at Maastricht University are organised according to the principles of problem-based learning, which involves lots of collaboration in small groups of students to solve unstructured, often open-ended, problems. Students are supposed to take the lead in discussing the problems, while the teacher has a facilitating role, see Wilkerson and Gijselaers (1996) for a detailed description. Tutorial groups are therefore small (at most 14 students), the tutor being either a staff member or a teaching-assistant. Students are required to attend at least 7 out of 9 tutorials.

The exam consists of 40 multiple choice questions. Students who fail the exam have the opportunity to retake the exam two months later, right after the exams of the courses taught in the second period and after the Christmas holidays. Students who passed the first sit exam are not allowed to participate in the resit. As a preparation for the exam, students have the opportunity to participate in three midterm tests, which allow them to acquire a bonus score of at most $20 \%$ of the maximum score in the final exam. These midterm tests are administered on the computer. Final exam grades are always expressed on a scale 1 (lowest) to 10 (highest), where 5,5 is the minimum grade required to pass the exam. The final passing rate in our sample is $92 \%$, and $77 \%$ of students passes after the first attempt.

A special feature of this course is its use of an electronic learning environment, MyLab, which accompanies Pearson's textbooks in mathematics and statistics. ${ }^{4}$ Students are supposed to use MyLab to practice the course material and prepare for the midterm tests. MyLab improves the efficiency of the learning process when students are heterogeneous in terms of prior education. Every week, students are supposed to solve a set of problems related to the topics covered in that week. Each topic is introduced by a test problem to assess existing skills and knowledge. Students who master the material will solve the problem, and move on to the next topic. Students who do not fully master the material may ask for assistance ("Help Me Solve This"), or for a step-by-step work example ("View an Example"). Students will continue receiving similar problems until they are able to solve them without the use of the assistance tools. When they succeed, they automatically move on to the next topic. Students who do not manage to solve the problem without use of the electronic assistance tools may decide to move on to the next topic manually. Students who completed all topics, but nevertheless feel that they need additional practice, can restart a topic, in which case MyLab provides new, similar exercises. A topic is considered completed when a student managed to solve the problem without help of the electronic assistance tools at least once. So, all students deal with the exact same topics, but students differ in the number of exercises, and hence time

\footnotetext{
${ }^{4}$ Pearson offers MyLab applications in several disciplines. The course Quantitative Methods 1 uses mathematics and statistics applications, named MyMathLab and MyStatLab, respectively. See http://www.mymathlab.com and http://www.mystatlab.com for further information.
} 
needed, to complete each topic, as well as the number of topics completed, and the number of additional exercises after a topic has been completed. MyLab records the fraction of topics completed, as well as the total number of exercises provided. Furthermore, MyLab records the amount of time each student is logged in. The system automatically logs off after 30 minutes of inactivity. MyLab is an important course tool, as it provides a particularly good preparation for the midterm exams.

Other data were collected by means of a number of on-line questionnaires during the course period. Those questionnaires were mainly concerned with student motivation and learning styles. ${ }^{5}$ In the final week of the course, students had to write an assignment in which they compare their responses with the average responses on a number of these questionnaires' items. As a result, all first-year students filled out these questionnaires. We measured risk and time preferences in the questionnaire administered in week 6 of the course.

\subsection{Performance measures}

We collected information on students' performance in the course QM1, as well as information on performance in all other first-year courses. In case of QM1, we investigate two measures of performance: the first sit exam grade, and whether a student passed or failed the first sit exam. We do not consider results obtained in the resit exam, as it is cleaner to focus on the results obtained in the first sit exam: all students take the exact same test and have the same opportunities to prepare.

For all other courses, we have four measures of performance. In analogy with our performance measures in the course QM1, we investigate the grade point average (GPA), weighted by the number of study credits, of all first sit exams, as well as the number of first sit exams failed in the first year. Further, we investigate the number of course credits (ECTS) obtained, and whether a student receives a negative binding study advice, i.e. drops out as a result of failing to meet the performance requirements explained above. These measures differ in the time horizon over which negative consequences of weak performance materialize, the probability with which those consequences will be realized, and the severity of those consequences. Theoretically, we would expect that the relation between grades and patience is stronger than the relation between passing the exam and patience, as the benefits of obtaining a higher grade materialize in the remote future, while failing an exam has more immediate consequences. ${ }^{6}$ Likewise, we would

\footnotetext{
${ }^{5}$ Students were informed that these data would remain confidential, and used in anonymous format for research purposes as well as improvement of QM1 education. Research using these data is described in Tempelaar et al. (2012, 2013a, 2013b).

${ }^{6}$ On the other hand, a substantial number of students do not have the ambition to obtain a high grade, but primarily care about passing the course. When those type of stu-
} 
expect that impatient students are willing to risk failing an exam, but not if failing will lead to a negative binding study advice (BSA). Stated otherwise, when failing an exam significantly increases the risk of failing to meet the BSA criteria, we would expect that the expected benefits of effort are so high that a rational student exerts maximal effort regardless of his time preferences. When impatient students are more likely to receive a negative BSA, we can interpret this as an indication of self-control problems.

\section{$2.3 \quad$ Effort}

Our first measure of effort is the total amount of time a student is logged in in the electronic learning environment, MyLab. The main advantage of this measure is its objective and precise measurement. As we shall see, time logged in in MyLab has strong predictive power for the first sit exam grade QM1. The median amount of time spent in MyLab is about 7 hours per week. This is a substantial part of their total study time, as students are supposed to spend 20 hours per week on this course, including obligatory attendance of 3 hours of tutorials. A potential limitation is that a student does not need to be active in MyLab during the time he is logged in: only after 30 minutes of inactivity a student is automatically logged off. The actual study time is therefore measured with error. This seems not a severe problem, however, as time logged in in MyLab is strongly related to the number of exercises generated by MyLab (pairwise correlation: 0.51), suggesting that students who are logged in are generally active during that time. None of our results change qualitatively when we use the number of exercises provided instead of time spent in MyLab. ${ }^{7}$ A second limitation is that we do not observe study efforts outside MyLab, for instance studying written course material or attending lectures. However, study efforts in and outside the electronic learning environment are unlikely to be substitutes, as time spent in MyLab also has strong predictive power for grades obtained in other courses, as we shall see. ${ }^{8}$

Since accurate measurement of effort is essential, we have two other measures of study effort. The first measure is based on practice results in the electronic learning environment. As explained above, MyLab does not only record the amount of time spent, but also keeps track of the fraction of prob-

dents constitute the majority, we expect stronger effects of impatience on the probability of passing the exam than on the exam grade obtained.

${ }^{7}$ We do not use the number of exercises provided as a measure of effort, as it may be sensitive to differences in learning style (e.g. trial and error), and it ignores the time students spend studying while trying to solve an exercise. The correlation with grades is therefore somewhat lower.

${ }^{8}$ As a robustness check, our questionnaire in week 6 asked students to indicate the average total number of hours spent on the course QM1 each week. As self-reported measures may suffer from potentially important biases, we do not present results using this measure. Results are qualitatively similar when we use this measure. 
lems the student manages to solve without electronic assistance. As MyLab records this information separately by week and subject (math and statistics), we sum the scores (i.e. the fraction of topics completed) obtained over the 6 weeks and rescale them to $0-100 \%$ scale. $^{9}$ Importantly, this measure addresses the two potential limitations of time spent in MyLab, as it reflects the intensity of study and, to a lesser extent, study efforts outside MyLab. A disadvantage of this measure is that the fraction of topics completed also depends on ability. However, this seems a minor issue, as the difficulty level of the exercises is relatively low, and students can infinitely practice and ask for assistance when attempting to solve a problem. Succeeding in solving an exercise without help of the assistance tools is therefore primarily a matter of effort. This is reflected in a high median score $(92.2 \%)$ and a strong correlation with the amount of time logged in in MyLab (0.60, see Table 1 below).

The third measure of effort is participation in an online summer course that takes place each year during the three months preceding the start of the academic year. The university offers this course in response to increasing numbers of students that start their studies with a deficiency in mathematics. The course is advertised at the web pages describing the Economics and Business study programmes, and at a web page that offers practical information for prospective first-year students. Moreover, all students who receive their proof of admission are informed about the course by email. Participation is voluntary, but recommended for students who were on a high school track involving little mathematics, which is about $2 / 3$ of our sample. Students can take a 10-15 minutes online entry test to identify deficiencies in their mathematical skills. The course takes about 80 hours of study, depending on pre-existing knowledge, and is entirely online. ${ }^{10} \mathrm{In}$ 2012 , costs of participating were $€ 50$.

\subsection{Time preferences}

Data on time and risk preferences were collected by means of the online questionnaire that was administered in week 6 of the course. Specifically, time preferences were measured with the following hypothetical question:

Suppose someone you fully trust offers you a gift of $€ \mathbf{1 0 0 0}$ today. However, he tells you that you can wait for one year and receive $€ \mathbf{1 1 0 0}$ instead. Which would you prefer?

a) $€ 1000$ now

\footnotetext{
${ }^{9}$ This procedure is preferable over calculating the unweighted fraction of completed topics, i.e. dividing the sum of completed topics by the total number of topics. The reason is that the number and difficulty level of exercises differs by week and subject. Our procedure ensures that weeks with few, but difficult exercises get a higher weight.

${ }^{10}$ For further information, see http://www.maastrichtuniversity.nl/web/Faculties/SBE/Theme

/Departments/QuantitativeEconomics/Floating_Pages_QE/OnlinePreparatoryCourses.htm
} 
b) $€ 1100$ in a year from now

This question was repeated two times, where the postponed amount was subsequently changed to $€ 1050$ and $€ 1250$. The idea behind those questions is that most individuals prefer the immediate payment when the delayed payment is low, but switch to the delayed payment when the latter amount is high enough. The amount for which individuals switch to the delayed payment is our measure of impatience. Hence, we can distinguish between individuals who always prefer the delayed payment (most patient), those who switch when the amount is $€ 1100$ or $€ 1250$, and those who always prefer the immediate payment (most impatient). Out of the 882 students who filled out our questionnaire, 20 students did not answer this question, while 7 individuals provided inconsistent answers, and are therefore dropped from the analysis. ${ }^{11}$ We decided to use hypothetical payoffs rather than real monetary payoffs, because our budget would limit the expected amount at stake to only a couple of euros. We do not think that when the stakes are so low, introducing real monetary payoffs would lead to more accurate measurement of preferences for present over future consumption, as consumption at any point in time will not be influenced by such low amounts. Falk et al. (2013) show that that non-incentivized measures of patience strongly correlate with incentivized measures obtained in the lab, see Dohmen et al. (2013) for a similar result on a self-assessed measure of impatience. ${ }^{12}$

\subsection{Ability/prior education}

It is important to correct for intelligence and, relatedly, prior education, as both are potentially correlated with time preferences and study behavior. As mentioned in the introduction, a consistent finding in the literature is that time preferences are related to measures of intelligence. Likewise, when patient students spend more time on their studies in secondary education, they can be expected to enter university with more skills and knowledge, which gives them a head start in the course QM1. We employ two measures of intelligence and prior education. The first is the score on an entry test that took place the first week of the course. The test aimed to assess existing skills and knowledge and consisted of 21 multiple choice questions: 14 questions on mathematics and 7 on statistics. From the performance on this entry test, we construct two measures, one equating the number of correct answers in the mathematics part, the other one equating the number of correct answers

\footnotetext{
${ }^{11}$ Answers are considered as inconsistent when an individual prefers the postponed payment when this amount is relatively low, while preferring the immediate payment when the postponed payment is even larger.

${ }^{12}$ Incentivizing the measurement of time preferences is common in lab experiments (e.g. Kirby et al., 2005; Dohmen et al., 2010; Castillo et al., 2011; Sutter et al., 2013), but uncommon in surveys (e.g. Cadena and Keys, 2012; De Paolo and Gioia, 2013; Golsteyn et al., 2014).
} 
in the statistics part. The reason for keeping the two parts separate is that, although they both reflect to some extent intelligence and prior education, they measure different things. The first measure captures mathematical ability, which can be expected to be correlated with measures of IQ. The second measures statistical knowledge, which is less suitable as a proxy for IQ, but rather reflects differences in high school education. ${ }^{13}$

The second measure of ability is a dummy which takes value 1 if an individual followed an advanced mathematics track in high school. ${ }^{14}$ Apart from prior education, this variable may also proxy for intelligence, as more intelligent individuals are more likely to choose a mathematics major in high school.

\subsection{Control variables}

As noted in the introduction, time preferences may be related to risk preferences (Anderhub et al., 2001; Dohmen et al., 2010; Andreoni and Sprenger, 2012; and Sutter et al., 2013). It is therefore important to take risk preferences into account. Our measure of risk preferences is taken from the German Socio-Economic Panel and asks for individuals' stated willingness to take risks in general. It is measured on a 7-point scale, where 1 means highly risk averse and 7 fully prepared to take risks. Dohmen et al. (2011) and Vieider et al. (2013) show that this measure predicts actual behavior in incentivized lottery experiments, that it is correlated with risky behaviors in several domains, and stable across cultures. Therefore, despite its subjective nature, this seems an adequate measure of risk preferences in our setting. ${ }^{15}$

The questionnaire we administered in week 6 asked students to give their best estimate of their expected exam grade for this course. This question was incentivized as follows. Students whose estimated grade was within 0.25 points of their actual exam grade, participated in a lottery, in which two winners were randomly drawn. Both winners received a book voucher

\footnotetext{
${ }^{13}$ This is apparent from the fact that the score on the statistics part is hardly related to our performance measures, in contrast to the score on the mathematics part, see Table 1 below.

${ }^{14} \mathrm{~A}$ mathematical level is classified as advanced when it is the highest or one of the highest mathematical high-school levels offered in the country, i.e. vwo-b (Netherlands), Leistungskurs (Germany), international baccalaureate math hl (international baccalaureate), or mathmajor (self-identified by students as a high school math track).

${ }^{15} \mathrm{We}$ also measure attitude towards risks and losses by means of two paid financial lottery questions. However, as it turns out, a large number of subjects gives an inconsistent answer: 155 out of 882 students $(18 \%)$ did not report a unique switching point in both or either of the two questions. Substantial fractions of inconsistent decision makers are not uncommon: Harrison et al. (2002), and Meier and Sprenger (2010) find that $4 \%$ and $11 \%$ of adult subjects were inconsistent, respectively. In a sample of children (at most 16 years old), Bettinger and Slonim (2007) and Castillo et al. (2011) find that more than $30 \%$ of their subjects are inconsistent. To avoid losing those observations, we decided not to include those variables in the analysis and use the subjective measure only. Including the incentivized measures does not affect the results qualitatively.
} 
worth 20 euros. We chose to pay the winner a book voucher rather than plain money, because a book voucher is perhaps more likely to be perceived as a suitable prize. We use this information as a further indicator of ability and effort.

Maastricht University attracts sizeable numbers of foreign students, partly because of its location close to the Belgian and German border, but also because of the language of instruction (English), and its distinct educational philosophy. In our analyses, we include dummies for the most prevalent nationalities to capture cultural differences and differences in educational systems. ${ }^{16}$ Throughout, we also include dummies for the study program: Economics, Fiscal Economics, or International Business. Moreover, we collected measures for anxiety, persistence, and self-belief. Those measures are all constructed from the Student Motivation Scale (Martin, 2009). ${ }^{17}$ Finally, for the course in quantitative methods we have information on the tutorial group each student belongs to, as well as on the identity of each group's tutor. When possible, we include an indicator variable on whether the tutor was a staff member or a teaching assistant.

\subsection{Descriptive statistics}

Our final sample combines two datasets: students who filled out the questionnaire (882 obs.) and students who were recorded in the electroniclearning environment (910 obs.). Virtually all first-year students occur in at least one of the two datasets, and 868 students occur in both datasets. ${ }^{18}$ We exclude 7 students for whom the e-learning environment recorded more than 30 practice hours of mathematics or statistics in at least one of the weeks, which is probably a recording error. We also eliminate 27 individuals who did not provide a valid answer (i.e. an inconsistent answer or no answer at all, see above) to our questions measuring time preferences. Finally,

\footnotetext{
${ }^{16}$ We measure nationality rather than the country in which the student obtained his or her high school diploma. However, we observe that very few students obtain a diploma abroad. For instance, despite Maastricht being close to the Belgian and German border, only one of the 54 Belgian students and only 1 out of 458 German students obtained a Dutch high school diploma. In fact, just two of the 169 students with a Dutch high school diploma in our sample do not have the Dutch nationality. Conversely, just 4 students with Dutch nationality obtained a German diploma.

${ }^{17}$ Each concept was measured by four items. Examples of these items are: "When exams and assignments are coming up, I worry a lot" (anxiety); "If an assignment is difficult, I keep working at it trying to figure it out" (persistence); "If I try hard, I believe I can do my university work well" (self-belief). See Martin (2009) for details.

${ }^{18}$ Information from the exam administration on exam results and participation gives us some idea about the sample attrition. We identify 13 first-year students who do not occur in either of the two datasets. Further, we lose 42 cases who occur in one of the datasets, but not in both. $70 \%$ of those students obtains zero ECTS during the first year, another $10 \%$ passes exactly one course. We therefore think that it is fair to say that those students made a wrong study choice, and should therefore not be included in the sample, as we will argue above.
} 
we exclude 2 repeat students from the sample, and 33 students who leave the School of Business and Economics before Christmas. ${ }^{19}$ The reason for this latter requirement is that we are not interested in the relation between time preferences and making a correct study choice, and therefore exclude students who obviously made a wrong study choice. This leaves us with a sample of 799 observations. However, since not all students gave complete and consistent answers to all questions, the final number of observations in the analysis depends on the variables included.

Table 1 shows the pairwise correlations between the most important variables. This provides valuable information about the quality of our measures of study effort. The first thing to note is that our measures of effort are significantly positively correlated. In particular, as noted above, time logged in in MyLab is highly related $(\mathrm{r}=0.60)$ with the percentage of topics completed. This is a clear indication that solving the exercises is primarily a matter of effort rather than ability, although the correlation with the entry test score on mathematics is sizeable $(\mathrm{r}=0.21)$. Further, this indicates that students are generally active during the time they are logged in. As a second indication of the quality of our measures, the time spent in MyLab as well as the percentage of topics completed are significantly correlated with the grade obtained in the course QM1 ( $\mathrm{r}=0.15$ and $\mathrm{r}=0.53$, respectively).$^{20}$ Importantly, the correlation with other measures of academic performance is in the same order of magnitude and often even stronger, suggesting that our measures of effort are also related to effort exerted in other courses. The relation between participation in the summer course and academic performance is weaker, which is probably due to lower (unobservable) ability of summer course participants.

A number of other relevant observations can be made from Table 1. First, impatience is significantly negatively correlated with most measures of performance (ECTS and BSA being the expectations), but not with any of the effort measures. As we will see, this largely corresponds to the findings

\footnotetext{
${ }^{19}$ For financial reasons, the majority of repeat students do not have an individual license for MyLab. Hence, only two repeat students are recorded in the electronic learning environment.

${ }^{20}$ In fact, the correlation between time spent in MyLab and the grade obtained in the course QM1 depends strongly on the percentage of topics completed. The correlation is 0.20 for students who completed a below median number of topics (i.e. less than $92,2 \%$ ) and -0.30 for students who completed an above median number of topics. This negative relation remains when we control for pre-education and entry test scores. The reason is that relatively unable individuals need more time to solve nearly all exercises than more talented individuals. Students who need more time to reach a given level of understanding can therefore be expected to obtain lower grades. We will only a observe a positive relation between study time and grades to the extent that individuals who spend more time on their studies on average reach a higher level of understanding. This condition is satisfied for low levels of understanding, when studying an additional hour leads to significant gains in understanding, but not when understanding of the course material reaches a natural maximum.
} 
in the regression analyses described in section 3. Second, in line with existing studies, students who perform better on the mathematics entry test are less impatient $(\mathrm{r}=-0.13)$. Interestingly, the grade in the course QM1 is highly predictive for grades in other courses $(\mathrm{r}=0.70)$ and academic performance in general. It is therefore safe to assume that the relation between impatience and actual study effort carries over to other courses, which is also in line with the strong positive correlation between measures of effort in the course QM1 and performance in other courses.

Figure A1 in the appendix shows the distribution of the answers to the time discounting question. Figure A2 shows the distribution of the math entry test scores, which is somewhat flatter than the normal distribution, but nicely symmetric. Figures A3-A8 display the distributions of the dependent variables used in the analyses, except for the binary variables passed first sit exam QM1 and participation in the summer course. About $77 \%$ of the sample passes the first sit exam QM1, and $20 \%$ participates in the summer course.

\section{Results}

\subsection{Performance}

We first investigate the relation between impatience and performance in the course QM1, where performance is measured by first sit exam grades and the probability of failing the first sit exam. The analysis of performance in the course QM1 is of particular interest, as we analyze the relation between impatience and study effort in the context of the course QM1. Then, we analyze other measures of academic performance in the first year in order to compare our results with those of the existing literature.

\subsubsection{Performance in the course QM1}

Table 2 reports the results of a Tobit estimation of individuals' first sit exam grade QM1 on their discount rates. As a significant fraction of students obtain the highest possible grade (see figure A3 in the appendix), we use a Tobit model to account for the right-censoring of the data. ${ }^{21}$ In all analyses, we use dummy variables to estimate the effect of time preferences. We distinguish between three patience categories, based on individuals' switchpoint in the time discounting question. The base category is formed by relatively patient individuals, namely individuals who always prefer the delayed payment and individuals who switch to the delayed payment when the amount is $€ 1100$. The reason for combining the two relatively patient categories into one category is that we do not have enough observations in

\footnotetext{
${ }^{21}$ We obtain similar results when we use OLS. Six students did not show up for the first exam QM1, and are treated as missing.
} 
the most patient category to obtain precise estimations. ${ }^{22}$ We use dummies because we do not know individuals' exact discount rate, but only the upper and/or lower bound. Moreover, the effect of individuals' discount rate on the dependent variable need not be linear.

The first column of Table 2 shows that the most impatient category of individuals obtains a significantly lower grade than the reference category, correcting for gender, age, study program, tutor quality, and nationality. The effect is not only statistically significant, but also meaningful in economic terms: the difference is about 1.1 point on a 10-point scale. The difference between the reference category and the category of individuals who switches when the delayed payment is $€ 1250$ is much smaller, and statistically significant only at the $10 \%$ level. This effect becomes insignificant once we add controls. In the second column of Table 2, we control for students' ability by adding their score on the entry tests and their score squared, taken in deviation from its mean, ${ }^{23}$ as well as a dummy for having obtained a mathematics major in high school. In line with existing studies (Cadena and Keys, 2012; De Paola and Gioa, 2013; Golsteyn et al., 2014), the point estimate decreases in magnitude, but remains sizeable and statistically significant. Next, we add controls for risk attitude and measures of personality, as time preferences are potentially correlated with risk attitudes and personality traits. We find a negative relation between students' self-reported willingness to take risks and their grade, while anxiety is also negatively associated with the grade QM1. This, however, has only a minor impact on the estimated effect of time preferences.

The key question is whether differences in impatient students' grades can be attributed to differences in study effort. As a first step in analyzing this question, we add controls for participation in the summer course as well as for time spent in MyLab, where we allow for decreasing returns by adding time spent in MyLab squared. ${ }^{24}$ As grades are ultimately a function of effort and ability, there is no theoretical reason why time preferences would be related to grades after controlling for effort and ability. The estimates are shown in column 4 of Table 2 . The coefficient of the most impatient category of individuals is unaffected. This suggests that impatient individuals' relatively weak performance cannot be attributed to impatient individuals

\footnotetext{
${ }^{22}$ We also did all our analyses with a separate dummy for the most patient category. The estimated coefficients of the two most patient categories are typically very similar. Results are available upon request.

${ }^{23}$ Throughout, squared terms are taken in deviation from their mean in order to prevent multicollinearity.

${ }^{24}$ The results are very similar when we replace total time spent in MyLab by time spent on mathematics and statistics separately. Also, we estimated a model that includes the interaction between time spent in MyLab on mathematics and statistics and the entry test scores on both subjects, as well as entry test scores squared. These interaction terms are typically insignificant, regardless whether both linear and quadratic terms are included, or just one of the two.
} 
exerting less effort. In column 5, we further control for effort and ability by adding individuals' expected grade and the percentage of topics completed. ${ }^{25}$ Although these variables add substantial explanatory power, their inclusion has only a minor effect on the estimated relation between patience and the exam grade QM1. So, as hypothesized, we find a negative relation between the exam grade QM1 and impatience, which is completely driven by the category of most impatient individuals. This relation can partially be explained by impatient individuals' lower ability and lower study efforts, but far from completely.

Arguably, the relation between patience and grades is stronger than the relation between patience and passing or failing the exam, as the benefits of obtaining a higher grade materialize in the remote future, while failing the exam has more immediate consequences. Table 3 presents the results of estimating a probit model, where the dependent variable takes the value 1 if a student failed the first sit exam QM1, and 0 otherwise. Coefficients report mean marginal effects. Column 1 shows that individuals who always prefer the immediate payment have a 12.5 percentage point higher estimated probability of failing the exam than the reference category, correcting for gender, age, study program, tutor quality, and nationality. This effect is substantial, as only $23 \%$ of our sample fails the first exam QM1. The point estimates become smaller when we add controls for ability, risk attitude, and other personality characteristics (columns 2-3). Still, the effect sizes remain substantial in absolute terms, and remain statistically significant at the $10 \%$ level. Again, correcting for study effort (columns 4 and 5) does not affect the estimated effect of impatience.

\subsubsection{Performance in other courses}

An important question is to what extent the relation between patience and study results in the course QM1 is representative for other courses. To answer this question, we examine the relation between patience and academic performance in other first-year courses than QM1. Our first measure of performance is the GPA, i.e. the ECTS-weighted average of the exam grades obtained in all first year courses except QM1. We only consider exam grades obtained in the first attempt and exclude results obtained in the resit. ${ }^{26} \mathrm{We}$

\footnotetext{
${ }^{25}$ We drop the quadratic terms of time spent in MyLab. The time spent in MyLab should be largely irrelevant after controlling for the percentage of topics completed, because what matters is a thorough understanding of the course material, and not so much the time needed to reach that particular level of understanding. This also explains the (small) negative effect of time spent in MyLab: students who spent more time to complete a certain fraction of topics, are probably of lower (unmeasured) ability. We obtain similar results when we divide the percentage of topics completed by the time spent in MyLab, thus creating an additional measure of ability.

${ }^{26}$ Results are similar when we investigate average final grades, i.e. including the resit results in the average. This is unsurprising, given that the correlation between the average
} 
estimate the model using OLS, as the distribution of the GPA is not censored, see figure A4 in the appendix.

The first five columns of Table 4 show the results of regressing the GPA on the same set of controls as before (except for tutor quality). The first thing to note is that, regardless of the exact specification, the most impatient category of individuals obtains significantly lower grades than individuals who are more patient. In fact, the relation between patience and the GPA is virtually the same as the relation between patience and the grade obtained in the course QM1. The estimated effect sizes are similar after standardizing: correcting for ability, risk attitude, and personality, the expected grade of the most impatient students is about one quarter of a standard deviation lower than the expected grade of the reference category, both in the course QM1 and in all other courses. In this sense, the relation between patience and grades we observe in the context of QM1 seems highly representative for other first year courses.

The second thing to note is that although our measures of ability and effort are obtained in the specific context of QM1, they are strongly related to the average grade obtained in other courses. The measures of ability jointly add substantial explanatory power, as shown by the difference in $\mathrm{R}^{2}$ between columns 1 and 2 . The various measures of effort are related to the GPA in the same way as when the grade QM1 is the dependent variable. Those results confirm the intuition we derived from inspecting the simple correlations between variables (Table 1), namely that our measures of ability and effort are very well able to explain academic performance in the first year. Nevertheless, the negative relation between impatience and grades does not vanish after controlling for ability and effort, see columns 4 and 5 of Table 4 . The relation becomes statistically insignificant only when we add the grade obtained in the course QM1 as explanatory variable, see column 6 of Table 4. By doing so, we extensively control for effort and ability. The grade QM1 is strongly $(\mathrm{t}=18.3)$ related to the GPA obtained in all other courses, and the $\mathrm{R}^{2}$ is increased from 0.41 to an impressive 0.60 . However, since the grade QM1 also depends on time preferences, it is unclear whether the relation between GPA and patience becomes insignificant because we perfectly control for effort and ability, or because of multicollinearity. In any case, the results reported in Table 4 show that impatient individuals obtain lower first sit exam grades, and that this cannot easily be explained by differences in effort and ability.

Next, we assess whether impatient students' lower GPA also translates into a higher probability of failing an exam. Specifically, we count the number of courses (other than QM1) in which a student failed the first sit exam, conditional on participating in that exam. Not participating in the first sit exam of a course is not considered as a failed exam, since we do not know

grade based on first sit and final grades is 0.98 . 
the grade the student would have obtained if he had participated. ${ }^{27}$ We estimate a negative binomial count model that corrects for exposure to the number of first sit exams taken. The estimation results, presented in the first two columns of Table 5, are comparable with the results on GPA: students who belong to the most impatient category fail more first sit exams. The effect is sizeable: the most impatient category fails about $28 \%$ more exams than the reference category, which amounts to 0.5 additional failed exam per academic year. Thus, the most impatient individuals do not only obtain lower grades in the first sit exams, they are also more likely to fail these exams.

An important question from the perspective of social welfare is whether impatient students obtain fewer ECTS in the first year. This is not implied by lower performance in the first sit exams: impatient students may perform relatively well in the re-examinations, and consequently obtain a similar number of ECTS as less impatient students. As the distribution of ECTS is naturally bounded between 0 and 60 ECTS, with the majority $(54 \%)$ of students obtaining the highest possible number of ECTS and a negligible $(2 \%)$ number obtaining zero ECTS, we first estimate a probit model where the dependent variable equals 1 when a student passes all courses, and 0 otherwise. The results are reported in columns 3 and 4 of Table 5 . The most impatient category of students has a roughly 11 percentage point smaller chance of passing all first year courses than the reference category (column 3). This is a substantial effect, given that $54 \%$ of the sample obtains 60 ECTS. However, the estimated effect reduces to 7 percentage points when we control for ability, risk attitude, and personality, and is no longer statistically significant $(\mathrm{p}=0.15)$. Moreover, the effect seems restricted to the extensive margin (i.e. obtaining all ECTS or not). When we estimate an OLS regression on the sample of students who do not obtain all ECTS, we do not find any relation between impatience and the number of ECTS obtained (see column 5 of Table 5). Unreported regressions show that this result continues to hold when we exclude students with particularly bad performance in terms of the number of ECTS obtained (using various thresholds), and when we exclude students who fail to meet the BSA requirements. Also, we do not find a statistically significant relationship when we combine intensive and extensive margin by estimating a count model. ${ }^{28}$ So, although the most

\footnotetext{
${ }^{27}$ Clearly, students who do not show up at the exam may do so for a specific reason. For instance, students may stay at home because they expect to fail anyway, or because their strategy is to take the resit exam later in the year, as the additional time allows for a better preparation. We therefore checked whether participation in a course's initial exam is related to impatience, and do not find a statistically significant relation between the two. We also redid our analysis assuming that students who did not participate, failed the exam. This does not affect the qualitative results.

${ }^{28} \mathrm{We}$ also find no differences between high and low ability students, as measured by their math entry test score. More generally, we will analyze the interaction between impatience and ability in more detail in section 4 .
} 
impatient category of students unambiguously shows worse performance in first sit exams than more patient students, this is not clearly reflected in a lower number of ECTS.

In columns 6 and 7 of Table 5, we analyze the relation between receiving a negative $\mathrm{BSA}$ and impatience. We estimate a probit model where the dependent variable equals 1 if a student received a negative BSA, and 0 otherwise. We find no indication that impatient students are more likely to receive a negative BSA than more patient students. In fact, the estimated coefficients of the impatience dummies are small relative to the percentage of students who receive a negative BSA (14\% of the sample), and typically go in the opposite direction from that predicted by theory. So, although highly impatient individuals show generally weaker academic performance, this remains without severe negative consequences by the end of the first year. This suggests that impatient individuals' lower performance is not due to severe self-control problems, but that there seems to be some rational trade-off underlying their relatively weak performance. ${ }^{29}$ Notice that this result is inconsistent with the results reported by Cadena and Keys (2012) and Golsteyn et al. (2014), who find that impatient individuals are more likely to drop out of high school and college. Of course, we cannot rule out that impatient students are more likely to drop out after the first year, but as drop out rates among students who survived the first year are relatively low, it seems safe to conclude that impatient students in our sample are not more likely to drop out as a consequence of putting in too little study efforts. $^{30}$

\subsection{Study efforts}

\subsubsection{Time logged in in MyLab}

In this section, we test the hypothesis that impatient individuals actually exert less study effort. As described above, we employ three different measures of study effort: recorded time logged in in MyLab, the percentage of topics completed, and participation in the on-line summer course, respectively. We use quantile regressions to estimate the relation between time logged in in MyLab and impatience, as the distribution of the dependent variable is highly right-skewed, see Figure A7. Using quantile regression instead of OLS makes the results more robust to outliers. ${ }^{31}$ Table 6 reports

\footnotetext{
${ }^{29}$ In line with this interpretation, we find that impatient individuals pass resit exams more often, but they do not generally obtain higher grades in resit exams.

${ }^{30}$ For instance, of the cohorts of students who started a Business study at Maastricht University in $2005,22 \%$ dropped out in the first year (107 students). Of the remaining students, only $4 \%$ dropped out in subsequent years (15 students).

${ }^{31}$ Results are similar when we use the log of time spent in MyLab or an indicator variable for spending an above median number of hours as dependent variable. Likewise, using OLS instead of quantile regressions does not affect the qualitative results.
} 
the estimation results. In columns 1-3, we estimate our basic specifications with the usual controls. Controlling for ability, we observe no statistically significant differences between individuals with different switchpoints. Also, the point estimates are very small, given that the median number of hours spent in MyLab is 43 hours. In column 4 of Table 6, we add participation in the summer course to the regression. One might be concerned that when impatient students participate in the summer course more often, they need less study time during the course, leading to an underestimation of the effects of impatience. This, however, is not the case. The estimations reported in column 4 show that the qualitative results are not affected by the inclusion of summer course participation as a control variable. Note that students who participate in the summer course in fact spend much more time on their studies, as these students can be expected to be less able and more motivated than seemingly identical students.

In column 5 of Table 6 , we check the robustness of this result by excluding a number of outliers. In particular, we exclude all observations in which a student was logged in more than 20 hours in one of the weeks on one of the subjects (i.e., math or statistics), or more than 4 times the standard deviation from the mean in that week if this number exceeds 20 hours (which occurs in 4 out of 12 subject-week combinations). This criterion replaces the milder original criterion of more than 30 hours on one of the subjects in one of the weeks. The results are largely unaffected by the exclusion of these 17 outliers. Unreported regressions show that we obtain similar results when we exclude students who were logged in for more than, respectively, 100, 80, or 60 hours in total: there is no clear relationship between time preferences and time logged in in MyLab.

\subsubsection{Score on problems solved}

Next, we assess the relation between impatience and the percentage of topics completed in MyLab. As many students manage to solve most of the problems (median: 92.2\%), we distinguish between students with an above median score and a below median score. We estimate a probit model, where 1 refers to students with a score above the median. The estimated mean marginal effects are reported in the first three columns of Table 7. Impatient students are estimated to be 10 percentage points less likely to obtain an above median score than the reference category, even after correcting for ability, risk attitude, and personality. This result, however, is not very robust. In column 4 of Table 7, we distinguish between students who complete all topics ( $16 \%$ of the sample), and those who do not. We do not find a statistically significant relationship. In column 5 , we concentrate the analysis on individuals who complete a below median number of topics. We regress the percentage of topics completed on time preferences, demographics, ability, risk attitude, and personality, conditional on solving less than $92.2 \%$ of 
the problems. We do not find any relation between time preferences and the percentage of topics completed. We obtain a similar result when we confine the sample to individuals who solve less than $100 \%$ of all topics (regression is not reported). So, we find a negative association between impatience and the percentage of topics completed in MyLab, but only on a rather specific margin, namely completing almost all topics or not.

\subsubsection{Participation in summer course}

Finally, we investigate how time preferences relate to participation in the online summer course. Table 8 presents the results of estimating a probit model, where the dependent variable equals 1 when a student participated in the summer course. The first two columns show estimates on the full sample. We observe no statistically significant differences between impatient students and the reference category. Unreported regressions show that students who always prefer the delayed payment are estimated to be 9 percentage points more likely to participate than less patient students, and that this effect is significant at the $5 \%$ level. However, when we compare students who always prefer the delayed payment with the most impatient category, the difference is not statistically significant.

One might argue that the relationship is stronger for students with a weak background in mathematics. Theoretically, students weigh the costs and future benefits of participating in the summer course. One would expect that students with a better high school education in mathematics perceive both the benefits and the effort costs as lower. As individual differences in time discount rates play a larger role when future benefits are high, we would expect a stronger relation when we restrict the sample to students with a weak background in mathematics. In columns 3 and 4 of Table 8 , we restrict the sample to students who were on a high school track in which mathematics was a major or a minor subject, respectively. Contrary to our expectations, we find no relation in the sample of students with a weak background in mathematics. If anything, it seems that among students who took a major in mathematics, the most patient students are more likely to participate. When we combine the two most impatient categories into one dummy, the difference comes close to significance $(\mathrm{p}=0.12)$. However, given the small number of observations, we should not overinterpret this finding.

\section{Robustness checks}

In this section, we conduct two robustness checks. First, we analyze how the relation between time preferences, academic performance, and study effort depends on ability. Second, building on that analysis, we reanalyze the relation between patience and time spent in Mylab conditional on the 
percentage of topics solved, as we would expect weaker effects of impatience among students who demonstrate good understanding of the course material.

\subsection{Heterogeneity in ability}

From a theoretical perspective, there is an ambiguous relation between ability and the effect of impatience on study behavior. One reason is that it is a priori not clear whether effort and ability are complements or substitutes. Another reason is that the marginal benefits of effort may be characterized by strong nonlinearities. Suppose students choose effort to maximize the following utility function:

$$
u=\delta f(e, a)-c(e),
$$

where $f(e, a)$ and $c(e)$ denote, respectively, the future benefits and present costs of study effort $e$, while $a$ denotes ability and $\delta$ captures patience. Assuming the problem is concave, i.e. $f_{e}>0, f_{e e} \leq 0, c_{e}>0$, and $c_{e e}>0$, it is easily verified that the optimal effort level is increasing in patience $\delta$ :

$$
\frac{d e}{d \delta}=\frac{f_{e}}{c_{e e}-\delta f_{e e}}>0
$$

The impact of a change in $\delta$ on optimal effort depends on the magnitude of the terms $f_{e}$ and $c_{e e}-\delta f_{e e}$. Patience has only a minor effect on the choice of effort when the marginal benefits of effort $f_{e}$ are small, when additional effort becomes increasingly costly (i.e. when $c_{e e}$ is large), and when the benefits of additional effort decline rapidly (i.e. when $f_{e e}$ is small). The effect of a change in ability depends on how this change affects these three terms, either directly $\left(f_{e a}\right.$ and $\left.f_{e e a}\right)$, or indirectly via the implied change in optimal effort $\left(\frac{d e}{d a} \frac{d e / d \delta}{d e}\right) .{ }^{32}$ The magnitude of $\frac{d e}{d \delta}$ therefore depends on ability, but how exactly is impossible to say without imposing additional assumptions.

The change in the numerator $f_{e}$ in response to a change in ability depends on the sign of the cross-derivative $f_{e a}$, which is a priori unclear. On the

${ }^{32}$ The effect of a change in ability is described by

$$
\frac{d e}{d \delta d a}=\frac{f_{e a}}{c_{e e}-\delta f_{e e}}+\frac{\delta f_{e} f_{e e a}}{\left[c_{e e}-\delta f_{e e}\right]^{2}}-\frac{d e}{d a}\left[\frac{f_{e e}}{c_{e e}-\delta f_{e e}}-\frac{c_{e e e}-\delta f_{e e e}}{\left[c_{e e}-\delta f_{e e}\right]^{3}}\right]
$$

The first term captures the change in the numerator of equation (1), its sign depending on the sign of $f_{e a}$. The second term captures the direct effect of $a$ on $f_{e e}$ in the denominator of equation (1) and can be positive or negative, depending on $f_{\text {eea }}$. The third term describes the effect of the change in optimal effort when ability changes, i.e. $\frac{d e}{d a} \frac{d e / d \delta}{d e}$, where $\frac{d e}{d a}=\frac{\delta f_{e a}}{c_{e e}-\delta f_{e e}}$. This gives after rewriting:

$$
\frac{d e}{d \delta d a}=\frac{f_{e a} c_{e e}+\delta f_{e} f_{e e a}}{\left[c_{e e}-\delta f_{e e}\right]^{2}}-\frac{\delta f_{e a}\left[c_{e e e}-\delta f_{e e e}\right]}{\left[c_{e e}-\delta f_{e e}\right]^{3}},
$$

which has an ambiguous sign. 
one hand, one might argue that students of high ability have low marginal benefits of effort, i.e. $f_{e a}<0$, since they will pass the exam with a decent grade anyway. On the other hand, one might argue that study efforts are more worthwhile for students who have the ability to obtain an outstanding grade, i.e. $f_{e a}>0$. A change in ability influences the denominator of equation (1) both directly and indirectly. There is a direct effect on $f_{e e}$ when $f_{e e a} \neq 0$, while there is an indirect effect on $c_{e e}-\delta f_{e e}$ via the implied change in optimal effort, $\frac{d e}{d a}$, which in turn depends on the sign of $f_{e a}$. This effect may have the opposite effect on $\frac{d e}{d \delta}$ as the change in the numerator, $f_{e a}$. As a result of these two effects, even if we would have a strong prior belief on the sign of $f_{e a}$, the effect of a change in ability is still indeterminate when the marginal cost and benefit functions are characterized by strong nonlinearities. ${ }^{33}$

So, from a theoretical perspective, the relation between time preferences, academic performance, and study effort may be different for low and high ability students, implying that we may obtain more precise estimates when we analyze both groups separately. Therefore, we split the sample in a low and high ability group, based on the scores on the mathematics entry test. Students with a score equal to or above the median are classified as high ability students, while students with a below median score are classified as low ability students.

Table 9 reports the results of re-estimating the relations between impatience, study results, and study effort by ability. In all regressions we include, in addition to the standard control variables, controls for ability, risk attitude, and personality. The key finding is that there are no clear, systematic differences between the two samples. The point estimates are in most cases comparable, although they often lose statistical significance due to the reduced sample sizes. So, we do not find that ability differences systematically influence the relation between time preferences, academic performance, and study effort.

\subsection{Time spent in MyLab and differences in understanding}

In this section, we apply the theoretical framework described above to the specific context of the course QM1, which allows us to impose more specific assumptions on the shape of the marginal benefit function. In particular, we assume that beyond a certain level of understanding of the course material, the marginal benefits of studying will decline rapidly towards zero, implying that the differences in effort between patient and impatient individuals will be small and hard to measure empirically. We expect that the differences

\footnotetext{
${ }^{33}$ For instance, assume that $c_{e e e}>0, f_{\text {eee }}<0$, and $f_{\text {ea }}<0$. As $f_{\text {ea }}<0$ implies that $\frac{d e}{d a}<0$, an increase in ability implies that marginal effort costs are lower and increase less rapidly, while the benefits of additional effort decline less rapidly. Changes in impatience may therefore have a larger effect, despite lower marginal benefits of effort $f_{e}$.
} 
will be more outspoken among students who do not demonstrate a good understanding of the course material. This prediction can be tested in the context of the course QM1, as we have information on students' level of understanding, namely the fraction of topics completed.

To fix ideas, abstracting from differences in ability, assume that above some effort level $\widehat{e}$ students understand the course material perfectly, and the marginal benefits of effort drop to zero. Stated otherwise, assume that there is a discontinuity in the marginal benefits of effort:

$$
\left\{\begin{array}{l}
f_{e}>0 \text { if } e<\widehat{e} \\
f_{e}=0 \text { if } e \geq \widehat{e}
\end{array}\right.
$$

When the marginal effort cost function has a sufficiently flat slope, all students choose $\widehat{e}$. In other words, all students work until they have a full understanding of the course material, regardless of their time preferences. Patience only plays a role when the marginal effort cost function is relatively steep, implying that the optimal level of effort $e<\widehat{e}$, and that students accept a lower understanding of the course material.

This example illustrates a more general intuition. One might argue that the marginal benefits of effort are characterized by an inverse S-shape: the first hours of study highly contribute to a better understanding of the course material, but beyond a certain level of understanding, the marginal benefits of effort decline rapidly, finally leveling off at zero. When the marginal benefits of effort decline rapidly, the differences in effort between patient and impatient individuals will be small and hard to measure empirically. Interpreting $f(e, a)$ as the level of understanding, ${ }^{34}$ this can easily be seen from equation (1): when $f_{e e}$ goes to $-\infty$, $\frac{d e}{d \delta}$ approaches zero. Arguably, students who fully understand the course material equate marginal cost and benefits where $f_{e}$ is small and/or steeply declining in effort, implying that impatience plays no role. By contrast, students who do not demonstrate a good understanding equate marginal costs and benefits where $f_{e}$ is larger and not yet steeply declining in effort, implying that differences in patience are more relevant. Differences in effort between students may be driven by differences in ability, as in the model described above, or by differences in motivation. ${ }^{35}$

To examine this empirically, we distinguish between students who show a good understanding of the course material and those who do not. In particular, we estimate the relation between time spent in MyLab and impatience

\footnotetext{
${ }^{34}$ Note that in the previous section, we interpreted $f(e, a)$ more broadly as the benefits of effort, which can be thought of as a function of the level of understanding. The shape of the marginal benefit function may be course-specific. In the case of QM1, it is reasonable to assume strong nonlinearities, as many students obtain one of the highest possible grades.

${ }^{35} \mathrm{~A}$ straightforward way to account for individual differences in motivation would be to add a term $\gamma e$ to the utility function. More motivated individuals, as represented by a higher value of $\gamma$, exert more effort $e$, which in turn affects $\frac{d e}{d \delta}$ via $f_{e}, c_{e e}$, and $f_{e e}$.
} 
for individuals who complete more than the median number of topics (i.e. at least $92.2 \%$ ), and for those who complete less, respectively. The difference between both subgroups in the correlation between time spent in MyLab and the grade obtained in the course QM1 indicates that this is a meaningful distinction. As noted above, this correlation is positive for students who complete a below median number of topics $(r=0.20)$, while it is negative for individuals who complete an above median number of topics $(\mathrm{r}=-0.30)$, This is consistent with the idea that beyond some effort level, additional hours do not lead to significant improvements in understanding of the course material, and therefore mainly reflect differences in ability.

The estimation results are reported in the first two columns of Table 10. We do not find a statistically significant relation in either of the two samples. ${ }^{36}$ In columns 3 and 4 , we repeat this exercise using a different cut-off level, namely the 75 th percentile (99.4\%). Again, we do not find a statistically significant relationship in either of the samples. The two most impatient categories of students seem to study fewer hours in the sample of students who complete at least $99.4 \%$ of all topics, but the difference with the reference category is far from statistically significant $(p=0.38$ when the two most impatient categories are combined into one dummy). In the light of these findings, it seems unlikely that the absence of a significant relationship between impatience and study effort is entirely driven by low and/or rapidly declining marginal benefits of effort.

\section{Discussion}

The overall picture that arises from our analyses is that impatient individuals show weaker performance, in particular when the consequences are not too severe (failing a first sit exam) or materialize in the remote future (GPA). However, we find no evidence that impatient students actually study fewer hours, and we also do not find clear differences in summer course participation. We find a negative relation between impatience and the percentage of topics completed, but this relation is not very robust. The question is how to reconcile these findings. If impatient students do not study fewer hours, why do they obtain lower grades? We can think of four possible explanations.

The first explanation is that impatient students do not spend less time on their studies, but they spend their time less effectively. For instance, impatient individuals may be more easily distracted, or have a different learning style. There are three reasons why we do not think this is a likely explanation. First, we would expect that differences in learning styles are reflected

\footnotetext{
${ }^{36}$ The number of observations differ between columns 1 and 2 , because we use the median of the fractions of topics completed in the basic sample. The loss in observations when we include additional variables is not spread evenly over the two groups. None of our results changes when we use the median of the estimation sample instead.
} 
in differences in the amount of time spent on each exercise generated by MyLab. However, we find no statistically significant differences, even after correcting for demographics, ability, and personality. This is in line with the fact that our qualitative results do not change when we use the number of exercises in the analyses rather than the amount of time spent on each exercise.

A second possibility is that impatient students allocate their study efforts differently over the course period. A relatively even distribution of study efforts over time is usually considered a more effective study strategy than an uneven distribution, e.g. postponing study efforts to the end of the course period, see Steel et al. (2001). Intuitively, one might expect that impatient individuals will be more inclined to procrastinate. However, we should keep in mind that in the course QM1, the midterm exams provide strong incentives not to do so. It is therefore unlikely that differences in the allocation of study effort over time play a role in this particular setting. Indeed, exploiting the fact that MyLab records study time on a weekly basis, we do not find differences in the allocation of study efforts over time. ${ }^{37}$

Third, we collected survey information on students' learning styles. This allows us to check whether impatient individuals report different learning styles, and if they do, to what extent these differences can explain impatient individuals' weaker performance. Based on the learning style model of Vermunt and Vermetten (2004), we distinguish between six different learning styles. These learning styles can be subdivided in three cognitive processing strategies, namely deep, stepwise, and concrete processing, and three metacognitive regulation strategies: self-regulation, external regulation, and lack of regulation. ${ }^{38}$ As it turns out, only deep processing is significantly correlated with time preferences $(\mathrm{r}=0.08)$. Given that self-reported learning styles and time preferences are hardly correlated, it is not surprising that none of our results is affected by the inclusion of these variables in the regressions. Thus, taken together, we find no indication that impatient students study less effectively.

The second explanation for our findings is that, by concentrating on time spent in an electronic learning environment, we ignore important other dimensions of study effort that explain impatient students' weaker perfor-

\footnotetext{
${ }^{37}$ We examine this hypothesis by running a panel regression with individual and week fixed effects, where the week fixed effects are interacted with dummies of individuals' time preferences. We do not find systematic differences in the allocation of study efforts over time.

${ }^{38}$ Deep processing is defined as relating elements of the subject matter to each other; stepwise processing (also called surface learning in several theories of learning) refers to learning facts, definitions, and separate elements of a theory; concrete processing means applying the subject matter. Self regulation means that students monitor their own learning process. Alternatively, the learning proces is regulated by external sources (assignments, learning objectives etc.) or poorly regulated, see Vermunt and Vermetten (2004) for details.
} 
mance. Since MyLab offers direct feedback and immediate rewards via text messages ("Correct!, Good!, Congratulations!, Fantastic!, Excellent!"), impatient students may have a relatively strong preference for using MyLab over studying written course materials, implying that we do not find differences in measured study effort, despite differences in total study effort. This explanation seems unlikely, because we capture study efforts outside the electronic learning environment by participation in the summer course and, to a lesser extent, the fraction of topics completed in MyLab. However, impatient students are not less likely to participate in the summer course than other students. Moreover, impatient students' lower first sit exam performance cannot be explained by differences in the fraction of topics completed. Furthermore, we find no differences when we use the total number of study hours students report in our questionnaire. Although we should be careful not to overinterpret this result, this finding is suggestive, and largely consistent with the result on summer course participation. Possibly, patient students put more effort in studying the written course materials the days before the exam. However, it is unlikely that this can explain the large divergence in exam performance, as time is limited and all students exert lots of effort the days before the exam. Therefore, we would expect that there is too little variation in study effort in this dimension to explain the large divergence in exam performance.

The third explanation is that impatient students prepare just as well for the exams as patient students, but they put in less effort to obtain a good result during the exam. This explanation would be in line with Borghans et al. (2008), who find that non-cognitive skills, including time preferences, influence performance on cognitive tests, even when those test are incentivized (see Segal, 2012, for a similar result). Although this explanation is in line with the patterns we observe in the data, it seems inconsistent to assume that impatient students have no difficulties with studying as intensively as patient students, while at the same time assuming that they are not able to put in similar effort during the exam, during which the marginal to returns to effort are so much higher than when practicing. We therefore do not think this is a plausible explanation.

The fourth explanation is that the relation between time preferences and study results is to some extent spurious. Several studies find that impatience is associated with lower scores on measures of intelligence, see e.g. Shamosh and Gray (2008). Because intelligence is typically measured with error, the negative relation between impatience and study results may be driven by the inability to sufficiently correct for differences in ability. For the same reason, we may not find the hypothesized negative relation between impatience and study efforts, as we would expect that, if anything, ability is negatively correlated with study efforts. So, even if impatient individuals study fewer hours, we may not find this because our estimations are upward biased.

The patterns in the data are very well in line with this explanation. 
First, in line with previous studies, we find that impatience and ability, as measured by the score on the mathematics entry test, are negatively correlated $(\mathrm{r}=-0.13)$. So, when we control for ability, we typically find that the relation between impatience and academic performance weakens. Second, it is suggestive that we find no relation between impatience and time spent in MyLab, whereas we find a positive relation between impatience and the percentage of topics completed. These two measures are highly correlated $(\mathrm{r}=0.60)$, but an important difference between the two is that the former is not related to the score on the math entry test $(\mathrm{r}=-0.03)$, while the latter is clearly positively correlated $(\mathrm{r}=0.21)$. Spurious correlation between impatience and intelligence can therefore perfectly account for this difference in findings.

As noted above, the inability to sufficiently correct for differences in ability may lead to overestimation of the negative effect of impatience on exam performance, as well as underestimation of the negative effect of impatience on study effort. The former relation seems more vulnerable to bias than the latter, as the correlation between ability and study effort is very small empirically (with the exception of the percentage of topics completed). Hence, if spurious correlation plays a role, the relation between impatience and study results is probably more severely biased than the relation between impatience and study effort. So, although the true effect of impatience on study efforts is uncertain, it is probably rather modest. Finally, it should be noted that spurious correlation can also arise because of other underlying variables than intelligence. A logical candidate is social background, which has been related to academic performance as well as time preferences (see Björklund and Salvanes, 2011, for a review on the effect of social background on educational attainment, and Delaney and Doyle, 2012, for evidence on the link between time preferences and social background). However, social background can be interpreted as unobserved ability, and therefore most likely leads to upward bias in the estimated effect of impatience on study results.

\section{Concluding remarks}

We analyze the relation between time preferences, study effort, and academic performance among first-year Business and Economics students. In line with previous studies (Kirby et al., 2005, Cadena and Keys, 2012, De Paola and Gioia, 2013, Golsteyn et al., 2014), we find a negative relation between impatience and first-year academic performance. In particular, impatient students obtain lower first sit exam grades, and fail first sit exams more often. However, we do not find statistically significant effects when the consequences of bad performance are more severe. Impatient students are not significantly less likely to obtain all first year's study credits, and they 
are not less likely to meet the university's minimal requirements for first year's performance. These findings suggest that impatient students' lower exam performance is not a consequence of impulsive behavior, but rather suggests that students make rational trade-offs, thereby avoiding strong adverse consequences of impatient behavior.

The main contribution of our study is that we relate time preferences to direct measures of study effort. In particular, we measure the time students spend practicing in an electronic learning environment, their practice results, and whether they participate in an online summer course. We find no evidence that impatient students study fewer hours or participate less often in the summercourse. Students' practice results are negatively related to impatience, but this relation appears not very robust. Our measures of effort therefore cannot explain impatient students' weaker first sit exam performance. The most likely explanation is that the relation between impatience and academic performance is to some extent spurious, as impatient individuals are of lower ability. To the extent that ability is unobserved or measured with error, the negative impact of impatience on academic performance is overestimated, and the impact on actual study efforts may be smaller than suggested by the differences in performance.

When interpreting those results, we should keep the specific setting in mind. Students face strong incentives to study regularly, as in most courses they have the opportunity to take at least one midterm test and they are required to attend weekly tutorials, where active participation is expected. In this sense, this is a strong test of the hypothesis that impatient students put less effort into their studies. Our findings are therefore not at odds with previous findings. However, the fact that we find substantial effects of impatience on grades and first sit exam results, despite insignificant differences in study hours, sheds new light on existing studies, as it suggests that the effects of impatience on educational performance are overestimated. This underlines the importance of using direct measures of study effort. 


\section{References}

[1] Andersen, Steffen, Glenn Harrison, Morten Lau, and Elisabet Rutström (2010). Preference heterogeneity in experiments: Comparing the field and laboratory. Journal of Economic Behavior and Organization, 73(2), 209-224.

[2] Anderhub, V., Werner Güth, Uri Gneezy, and Doron Sonsino. On the Interaction of Risk and Time Preferences: An Experimental Study. German Economic Review, 2(3), 239-253.

[3] Andreoni, James, and Charles Sprenger (2012). Risk Preferences are Not Time Preferences. American Economic Review, 102(7), 3357-76.

[4] Becker, Gary (1962). Investment in Human Capital: A Theoretical Analysis, Journal of Political Economy, 70(5), 9-49.

[5] Ben-Porath, Yoram (1967). The Production of Human Capital and the Life Cycle of Earnings. Journal of Political Economy, 75(4), 352-365.

[6] Bettinger, Eric, and Robert Slonim (2007). Patience among children. Journal of Public Economics, 91(1-2), 343-363.

[7] Björklund, Anders and Kjell Salvanes (2011). Education and family background: Mechanisms and policies. volume 3 of Handbook of the Economics of Education, chapter 3, pp. 201-247. Elsevier.

[8] Borghans, Lex, and Bart Golsteyn (2006). Time Discounting and the Body Mass Index, Evidence from the Netherlands, Economics and $\mathrm{Hu}$ man Biology 4(1), 39-61.

[9] Borghans, Lex, Huub Meijers, and Bas ter Weel (2008). The Role of Noncognitive Skills in Explaining Cognitive Test Scores, Economic Inquiry, 46(1), 2-12.

[10] Cadena, Brian, and Benjamin Keys (2012). Human Capital and the Lifetime Costs of Impatience. Working paper.

[11] Castillo, Marco, Paul J. Ferraro, Jeffrey L. Jordan, and Ragan Petrie (2011). The Today and Tomorrow of Kids: Time preferences and educational outcomes of children. Journal of Public Economics, 95(11), 1377-1385.

[12] Chabris, Christopher F., David Laibson, Carrie L. Morris, Jonathon P. Schuldt, and Dmitry Taubinsky (2008). Individual LaboratoryMeasured Discount Rates Predict Field Behavior. Journal of Risk and Uncertainty, 37 (2-3): 237-269. 
[13] De Paola, M., and Francesca Gioia (2013). Impatience and academic performance. Less effort and less ambitious goals. Università della Calabria Working paper 02-2013.

[14] Delaney, Liam, and Orla Doyle (2012). Socioeconomic differences in early childhood time preferences, Journal of Economic Psychology, $33(1), 237-247$.

[15] Dohmen, Thomas, Armin Falk, David Huffman, and Uwe Sunde (2010). Are Risk Aversion and Impatience Related to Cognitive Ability?, American Economic Review, 100(3), 1238-1260.

[16] Dohmen, Thomas, Armin Falk, David Huffman, Uwe Sunde, Jürgen Schupp, and Gert G. Wagner (2011). Individual Risk Attitudes: Measurement, Determinants, and Behavioral Consequences. Journal of the European Economic Association, 9(3), 522-550.

[17] Dohmen, Thomas, Armin Falk, David Huffman, Jürgen Schupp, Uwe Sunde, Thomas Vischer, Gert G. Wagner (2013). Validating an UltraShort Survey Measure of Patience. Economics Letters, 120(2): 142-145.

[18] Falk, Armin, Anke Becker, Thomas Dohmen, David Huffman, and Uwe Sunde (2013). An Experimentally Validated Preference Survey Module. Working paper.

[19] Frederick, Shane. (2005). Cognitive Reflection and Decision Making. Journal of Economic Perspectives. 19(4), 24-42.

[20] Golsteyn, Bart, Hans Grönqvist, and Lena Lindahl (2014), Adolescent Time Preferences Predict Lifetime Outcomes. Economic Journal, forthcoming.

[21] Harrison, Glen, Morten Lau, and Melonie Williams (2002). Estimating individual discount rates for Denmark: a field experiment. American Economic Review, 92(5), 1606-1617.

[22] Kirby, Kris, Gordon Winston, and Mariana Santiesteban (2005). Impatience and grades: Delay-discount rates correlate negatively with college GPA. Learning and Individual Differences 15(3), 213-222.

[23] Martin, Andrew (2009). Motivation and engagement across the academic life span: A developmental construct validity study of elementary school, high school, and university/college students. Educational and Psychological Measurement, 69(5), 794-824.

[24] Meier, Stephan and Charles Sprenger (2010). Present-Biased Preferences and Credit Card Borrowing. American Economic Journal, 2(1), 193-210. 
[25] Segal, Carmit (2012). Working When No One is Watching: Motivation, Test Scores, and Economic Success, Management Science, 58(8), 14381457.

[26] Shamosh, Noah A. and Jeremy R. Gray (2008). Delay Discounting and Intelligence: A Meta-Analysis. Intelligence, 36(4), 289-305.

[27] Steel, Piers, Thomas Brothen, and Catherine Wambach (2001). Procrastination and personality, performance, and mood. Personality and Individual Differences, 30(1), 95-106.

[28] Sutter, Matthias, Martin Kocher, Daniela Glätzle-Rützler, and Stefan Trautmann (2013). Impatience and Uncertainty: Experimental Decisions Predict Adolescents' Field Behavior. American Economic Review, 103(1), 510-531.

[29] Tempelaar, Dirk, Henk Cuypers, Evert van de Vrie, André Heck, Hans van der Kooij (2013a). Formative Assessment and Learning Analytics. In D. Suthers \& K. Verbert (Eds.), Proceedings of the 3rd International Conference on Learning Analytics and Knowledge, 205-209. New York: ACM.

[30] Tempelaar, Dirk, Alexandra Niculescu, Bart Rienties, Bas Giesbers, and Wim Gijselaers (2012). How achievement emotions impact students' decisions for online learning, and what precedes those emotions. Internet and Higher Education, 15(3), 161-169.

[31] Tempelaar, Dirk, Marold Wosnitza, Simone Volet, Bart Rienties, Bas Giesbers, and Wim Gijselaers (2013b). The role of self- and social directed goals in a problem-based, collaborative learning context. Higher Education, 66(2), 253-267.

[32] Vermunt, Jan, and Yvonne Vermetten (2004). Patterns in Student Learning: Relationships Between Learning Strategies, Conceptions of Learning, and Learning Orientations. Educational Psychology Review, 16(4), 359-385.

[33] Vieider, Ferdinand, Mathieu Lefebvre, Ranoua Bouchouicha, Thorsten Chmura, Rustamdjan Hakimov, Michal Krawczyk, and Peter Martinsson (2013). Common components of attitudes towards risk and uncertainty across contexts and domains: evidence from 30 countries. Working Paper.

[34] Wilkerson, LuAnn, and Wim Gijselaers (1996). Bringing problem-based learning to higher education: Theory and practice. San Francisco: Jossey-Bass. 


\section{Tables}

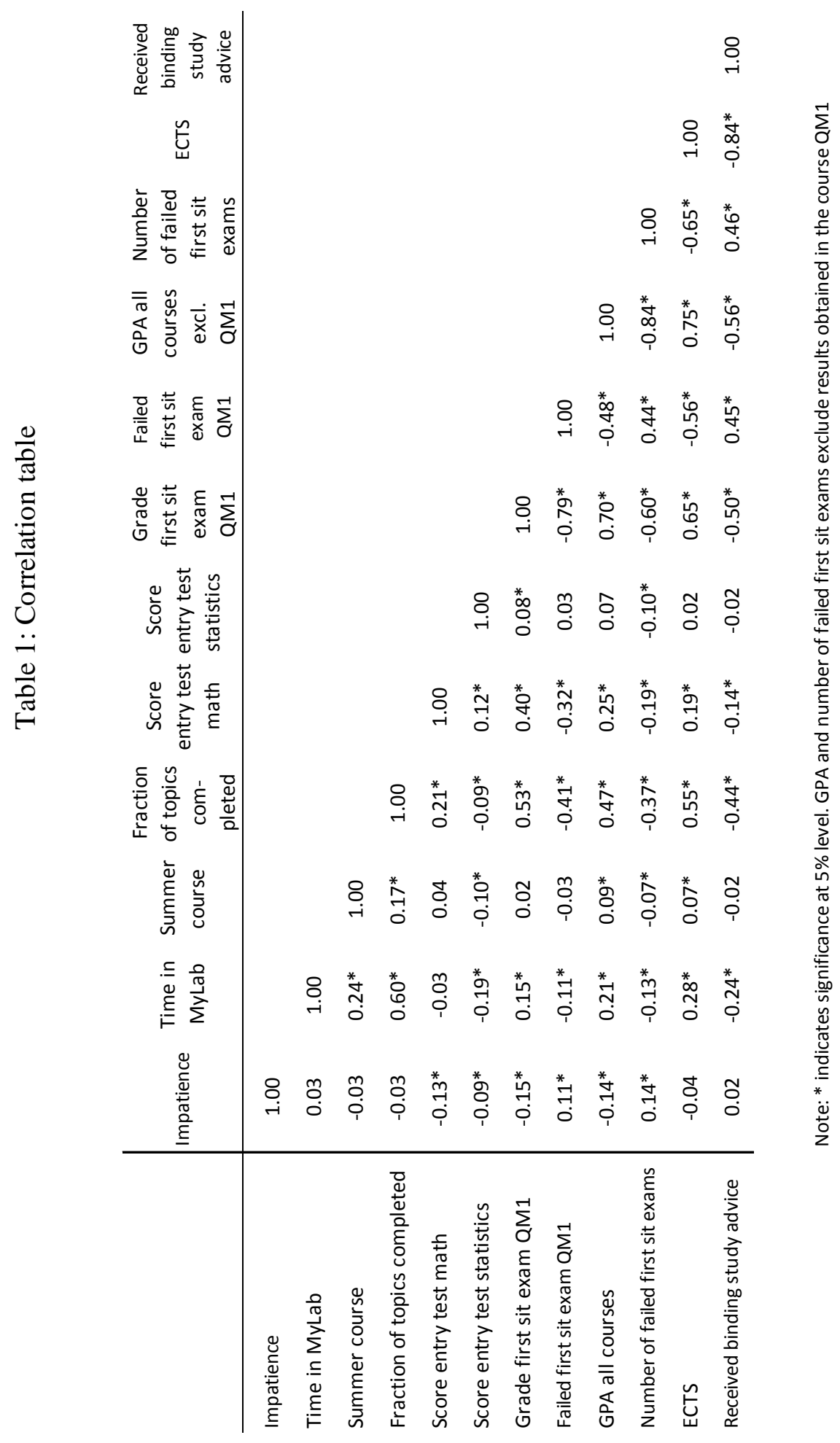


Table 2: Impatience and grades QM1

Method: Tobit

\begin{tabular}{|c|c|c|c|c|c|}
\hline & $(1)$ & $(2)$ & (3) & $(4)$ & (5) \\
\hline $\begin{array}{l}\text { Always delayed or switch when } \\
\text { delayed is } € 1100\end{array}$ & & & Reference & & \\
\hline Switch when delayed is $€ 1250$ & $\begin{array}{l}-0.380^{*} \\
(0.215)\end{array}$ & $\begin{array}{r}-0.159 \\
(0.192)\end{array}$ & $\begin{array}{r}-0.127 \\
(0.187)\end{array}$ & $\begin{array}{r}-0.257 \\
(0.179)\end{array}$ & $\begin{array}{r}-0.073 \\
(0.156)\end{array}$ \\
\hline Always Immediate & $\begin{array}{c}-1.102 * * * \\
(0.233)\end{array}$ & $\begin{array}{c}-0.726 * * * \\
(0.216)\end{array}$ & $\begin{array}{c}-0.628 * * * \\
(0.213)\end{array}$ & $\begin{array}{c}-0.649 * * * \\
(0.196)\end{array}$ & $\begin{array}{c}-0.475^{* * *} \\
(0.169)\end{array}$ \\
\hline Score entry test Math & & $\begin{array}{c}0.285^{* * *} \\
(0.033)\end{array}$ & $\begin{array}{c}0.262^{* * *} \\
(0.033)\end{array}$ & $\begin{array}{l}0.252^{* * *} \\
(0.032)\end{array}$ & $\begin{array}{l}0.112^{* * *} \\
(0.030)\end{array}$ \\
\hline$($ Score entry test Math)^2 & & $\begin{array}{l}-0.007 \\
(0.009)\end{array}$ & $\begin{array}{l}-0.008 \\
(0.009)\end{array}$ & $\begin{array}{l}-0.005 \\
(0.008)\end{array}$ & $\begin{array}{c}0.002 \\
(0.007)\end{array}$ \\
\hline Score entry test Statistics & & $\begin{array}{c}0.056 \\
(0.064)\end{array}$ & $\begin{array}{c}0.079 \\
(0.064)\end{array}$ & $\begin{array}{l}0.108^{*} \\
(0.062)\end{array}$ & $\begin{array}{l}0.122 * * \\
(0.053)\end{array}$ \\
\hline$($ Score entry test Statistics)^ 2 & & $\begin{array}{c}0.113^{* * *} \\
(0.032)\end{array}$ & $\begin{array}{c}0.100 * * * \\
(0.031)\end{array}$ & $\begin{array}{c}0.094^{* * *} \\
(0.029)\end{array}$ & $\begin{array}{l}0.056 * * \\
(0.027)\end{array}$ \\
\hline Mathematics major & & $\begin{array}{c}0.956 * * * \\
(0.193)\end{array}$ & $\begin{array}{c}0.863^{* * *} \\
(0.194)\end{array}$ & $\begin{array}{c}0.895^{* * *} \\
(0.185)\end{array}$ & $\begin{array}{c}0.650 * * * \\
(0.156)\end{array}$ \\
\hline Risk attitude & & & $\begin{array}{c}-0.185 * * * \\
(0.070)\end{array}$ & $\begin{array}{c}-0.142 * * \\
(0.066)\end{array}$ & $\begin{array}{r}-0.052 \\
(0.056)\end{array}$ \\
\hline Anxiety & & & $\begin{array}{c}-0.322 * * * \\
(0.067)\end{array}$ & $\begin{array}{c}-0.339 * * * \\
(0.064)\end{array}$ & $\begin{array}{c}-0.137 * * \\
(0.059)\end{array}$ \\
\hline Persistence & & & $\begin{array}{r}-0.086 \\
(0.112)\end{array}$ & $\begin{array}{r}-0.146 \\
(0.111)\end{array}$ & $\begin{array}{c}-0.285^{* * *} \\
(0.098)\end{array}$ \\
\hline Self-belief & & & $\begin{array}{c}0.152 \\
(0.132)\end{array}$ & $\begin{array}{c}0.141 \\
(0.122)\end{array}$ & $\begin{array}{r}-0.069 \\
(0.107)\end{array}$ \\
\hline Summer course & & & & $\begin{array}{c}0.046 \\
(0.199)\end{array}$ & $\begin{array}{r}-0.073 \\
(0.178)\end{array}$ \\
\hline Time in MyLab & & & & $\begin{array}{c}0.031^{* * *} \\
(0.004)\end{array}$ & $\begin{array}{c}-0.010 * * * \\
(0.004)\end{array}$ \\
\hline 1/100*(Time in MyLab)^2 & & & & $\begin{array}{c}-0.067^{* * *} \\
(0.008)\end{array}$ & \\
\hline Expected grade & & & & & $\begin{array}{c}0.709 * * * \\
(0.088)\end{array}$ \\
\hline Fraction of topics completed & & & & & $\begin{array}{c}4.174^{* * *} \\
(0.305)\end{array}$ \\
\hline Gender, Age, Nationality & yes & yes & yes & yes & yes \\
\hline Study Program and tutor quality & yes & yes & yes & yes & yes \\
\hline Observations & 791 & 779 & 778 & 778 & 769 \\
\hline Pseudo r2 & 0.02 & 0.07 & 0.08 & 0.10 & 0.16 \\
\hline
\end{tabular}


Table 3: Impatience and probability of failing exam QM1

Method: Probit (1=fail, $0=$ pass)

Failed first sit exam QM1

\begin{tabular}{|c|c|c|c|c|c|}
\hline & $(1)$ & $(2)$ & (3) & (4) & (5) \\
\hline $\begin{array}{l}\text { Always delayed or switch when } \\
\text { delayed is } € 1100\end{array}$ & & & Reference & & \\
\hline Switch when delayed is $€ 1250$ & $\begin{array}{c}0.031 \\
(0.036)\end{array}$ & $\begin{array}{c}0.005 \\
(0.034)\end{array}$ & $\begin{array}{c}0.004 \\
(0.034)\end{array}$ & $\begin{array}{c}0.026 \\
(0.034)\end{array}$ & $\begin{array}{c}0.009 \\
(0.032)\end{array}$ \\
\hline Always Immediate & $\begin{array}{c}0.125^{* * *} \\
(0.044)\end{array}$ & $\begin{array}{l}0.085^{* *} \\
(0.043)\end{array}$ & $\begin{array}{l}0.071 * \\
(0.042)\end{array}$ & $\begin{array}{l}0.084^{* *} \\
(0.042)\end{array}$ & $\begin{array}{c}0.069 * \\
(0.039)\end{array}$ \\
\hline Score entry test Math & & $\begin{array}{c}-0.038 * * * \\
(0.006)\end{array}$ & $\begin{array}{c}-0.035^{* * *} \\
(0.006)\end{array}$ & $\begin{array}{c}-0.034 * * * \\
(0.006)\end{array}$ & $\begin{array}{c}-0.019 * * * \\
(0.006)\end{array}$ \\
\hline$($ Score entry test Math)^2 & & $\begin{array}{c}0.001 \\
(0.002)\end{array}$ & $\begin{array}{c}0.001 \\
(0.002)\end{array}$ & $\begin{array}{c}0.000 \\
(0.002)\end{array}$ & $\begin{array}{l}-0.001 \\
(0.002)\end{array}$ \\
\hline Score entry test Statistics & & $\begin{array}{c}0.007 \\
(0.012)\end{array}$ & $\begin{array}{c}0.005 \\
(0.011)\end{array}$ & $\begin{array}{c}0.000 \\
(0.011)\end{array}$ & $\begin{array}{l}-0.003 \\
(0.011)\end{array}$ \\
\hline$(\text { Score entry test Statistics) })^{\wedge} 2$ & & $\begin{array}{l}-0.012^{*} \\
(0.006)\end{array}$ & $\begin{array}{l}-0.011^{*} \\
(0.006)\end{array}$ & $\begin{array}{l}-0.010^{*} \\
(0.006)\end{array}$ & $\begin{array}{l}-0.007 \\
(0.006)\end{array}$ \\
\hline Mathematics major & & $\begin{array}{c}-0.135^{* * *} \\
(0.030)\end{array}$ & $\begin{array}{c}-0.127^{* * *} \\
(0.030)\end{array}$ & $\begin{array}{c}-0.138 * * * \\
(0.029)\end{array}$ & $\begin{array}{c}-0.117^{* * *} \\
(0.027)\end{array}$ \\
\hline Risk attitude & & & $\begin{array}{c}0.014 \\
(0.012)\end{array}$ & $\begin{array}{c}0.007 \\
(0.012)\end{array}$ & $\begin{array}{r}-0.001 \\
(0.011)\end{array}$ \\
\hline Anxiety & & & $\begin{array}{c}0.035^{* * *} \\
(0.012)\end{array}$ & $\begin{array}{c}0.038 * * * \\
(0.012)\end{array}$ & $\begin{array}{c}0.017 \\
(0.012)\end{array}$ \\
\hline Persistence & & & $\begin{array}{c}0.037^{*} \\
(0.022)\end{array}$ & $\begin{array}{c}0.050 * * \\
(0.022)\end{array}$ & $\begin{array}{c}0.056 * * * \\
(0.021)\end{array}$ \\
\hline Self-belief & & & $\begin{array}{l}-0.045^{*} \\
(0.023)\end{array}$ & $\begin{array}{c}-0.042 * \\
(0.023)\end{array}$ & $\begin{array}{l}-0.019 \\
(0.021)\end{array}$ \\
\hline Summer course & & & & $\begin{array}{r}-0.046 \\
(0.033)\end{array}$ & $\begin{array}{r}-0.030 \\
(0.032)\end{array}$ \\
\hline Time in MyLab & & & & $\begin{array}{c}-0.004 * * * \\
(0.001)\end{array}$ & $\begin{array}{c}0.001^{*} \\
(0.001)\end{array}$ \\
\hline $1 / 100^{*}($ Time in MyLab)^2 & & & & $\begin{array}{c}0.009 * * * \\
(0.002)\end{array}$ & \\
\hline Expected grade & & & & & $\begin{array}{c}-0.069 * * * \\
(0.017)\end{array}$ \\
\hline Fraction of topics completed & & & & & $\begin{array}{c}-0.515^{* * *} \\
(0.066)\end{array}$ \\
\hline Gender, Age, Nationality & yes & yes & yes & yes & yes \\
\hline Study Program and tutor quality & yes & yes & yes & yes & yes \\
\hline Observations & 791 & 779 & 778 & 778 & 769 \\
\hline Pseudo $R^{\wedge} 2$ & 0.04 & 0.15 & 0.16 & 0.23 & 0.31 \\
\hline
\end{tabular}


Table 4: Impatience and GPA all courses except QM1

\begin{tabular}{|c|c|c|c|c|c|c|}
\hline \multirow[t]{2}{*}{ Method: OLS } & \multicolumn{6}{|c|}{ GPA all courses except QM1 } \\
\hline & (1) & $(2)$ & $(3)$ & $(4)$ & (5) & (6) \\
\hline $\begin{array}{l}\text { Always delayed or switch when } \\
\text { delayed is } € 1100\end{array}$ & & & Refe & nce & & \\
\hline Switch when delayed is $€ 1250$ & $\begin{array}{c}-0.094 \\
(0.105)\end{array}$ & $\begin{array}{l}-0.003 \\
(0.101)\end{array}$ & $\begin{array}{c}0.019 \\
(0.099)\end{array}$ & $\begin{array}{l}-0.035 \\
(0.096)\end{array}$ & $\begin{array}{c}0.060 \\
(0.088)\end{array}$ & $\begin{array}{c}0.069 \\
(0.069)\end{array}$ \\
\hline Always Immediate & $\begin{array}{c}-0.507^{* * *} \\
(0.113)\end{array}$ & $\begin{array}{c}-0.358^{* * *} \\
(0.113)\end{array}$ & $\begin{array}{c}-0.295^{* * *} \\
(0.112)\end{array}$ & $\begin{array}{c}-0.306^{* * *} \\
(0.106)\end{array}$ & $\begin{array}{l}-0.225^{* *} \\
(0.097)\end{array}$ & $\begin{array}{l}-0.096 \\
(0.083)\end{array}$ \\
\hline Score entry test Math & & $\begin{array}{c}0.113^{* * *} \\
(0.016)\end{array}$ & $\begin{array}{c}0.101 * * * \\
(0.017)\end{array}$ & $\begin{array}{c}0.098^{* * *} \\
(0.017)\end{array}$ & $\begin{array}{l}0.029 * \\
(0.017)\end{array}$ & $\begin{array}{l}-0.007 \\
(0.013)\end{array}$ \\
\hline$(\text { Score entry test Math })^{\wedge} 2$ & & $\begin{array}{c}0.005 \\
(0.004)\end{array}$ & $\begin{array}{c}0.004 \\
(0.004)\end{array}$ & $\begin{array}{c}0.005 \\
(0.004)\end{array}$ & $\begin{array}{l}0.008^{*} \\
(0.004)\end{array}$ & $\begin{array}{l}0.008 * * \\
(0.003)\end{array}$ \\
\hline Score entry test Statistics & & $\begin{array}{l}0.064^{*} \\
(0.033)\end{array}$ & $\begin{array}{l}0.076 * * \\
(0.033)\end{array}$ & $\begin{array}{c}0.096 * * * \\
(0.032)\end{array}$ & $\begin{array}{c}0.104^{* * *} \\
(0.029)\end{array}$ & $\begin{array}{c}0.073^{* * *} \\
(0.025)\end{array}$ \\
\hline$($ Score entry test Statistics)^2 & & $\begin{array}{c}0.024 \\
(0.015)\end{array}$ & $\begin{array}{c}0.016 \\
(0.014)\end{array}$ & $\begin{array}{c}0.012 \\
(0.014)\end{array}$ & $\begin{array}{l}-0.005 \\
(0.014)\end{array}$ & $\begin{array}{l}-0.020^{*} \\
(0.011)\end{array}$ \\
\hline Mathematics major & & $\begin{array}{c}0.128 \\
(0.096)\end{array}$ & $\begin{array}{c}0.078 \\
(0.096)\end{array}$ & $\begin{array}{c}0.112 \\
(0.094)\end{array}$ & $\begin{array}{c}0.010 \\
(0.084)\end{array}$ & $\begin{array}{c}-0.171 * * \\
(0.071)\end{array}$ \\
\hline Risk attitude & & & $\begin{array}{c}-0.122^{* * *} \\
(0.034)\end{array}$ & $\begin{array}{c}-0.102^{* * *} \\
(0.033)\end{array}$ & $\begin{array}{c}-0.065^{* *} \\
(0.030)\end{array}$ & $\begin{array}{c}-0.054^{* *} \\
(0.025)\end{array}$ \\
\hline Anxiety & & & $\begin{array}{c}-0.168^{* * *} \\
(0.034)\end{array}$ & $\begin{array}{c}-0.184 * * * \\
(0.033)\end{array}$ & $\begin{array}{c}-0.089 * * * \\
(0.031)\end{array}$ & $\begin{array}{l}-0.045^{*} \\
(0.024)\end{array}$ \\
\hline Persistence & & & $\begin{array}{l}-0.061 \\
(0.061)\end{array}$ & $\begin{array}{c}-0.101^{*} \\
(0.059)\end{array}$ & $\begin{array}{c}-0.161^{* * *} \\
(0.053)\end{array}$ & $\begin{array}{l}-0.073 \\
(0.045)\end{array}$ \\
\hline Self-belief & & & $\begin{array}{c}0.144^{* *} \\
(0.067)\end{array}$ & $\begin{array}{l}0.138^{* *} \\
(0.064)\end{array}$ & $\begin{array}{c}0.032 \\
(0.060)\end{array}$ & $\begin{array}{c}0.036 \\
(0.048)\end{array}$ \\
\hline Summer course & & & & $\begin{array}{c}0.023 \\
(0.111)\end{array}$ & $\begin{array}{l}-0.037 \\
(0.099)\end{array}$ & $\begin{array}{l}-0.010 \\
(0.080)\end{array}$ \\
\hline Time in MyLab & & & & $\begin{array}{c}0.016^{* * *} \\
(0.002)\end{array}$ & $\begin{array}{l}-0.002 \\
(0.002)\end{array}$ & $\begin{array}{c}0.001 \\
(0.002)\end{array}$ \\
\hline 1/100*(Time in MyLab)^2 & & & & $\begin{array}{c}-0.026^{* * *} \\
(0.005)\end{array}$ & & \\
\hline Expected grade & & & & & $\begin{array}{c}0.354^{* * *} \\
(0.046)\end{array}$ & $\begin{array}{c}0.153^{* * *} \\
(0.037)\end{array}$ \\
\hline Fraction of topics completed & & & & & $\begin{array}{c}1.813^{* * *} \\
(0.177)\end{array}$ & $\begin{array}{c}0.338^{* *} \\
(0.170)\end{array}$ \\
\hline Grade first sit exam QM1 & & & & & & $\begin{array}{c}0.370^{* * *} \\
(0.020)\end{array}$ \\
\hline Gender, Age, Nationality & yes & yes & yes & yes & yes & yes \\
\hline Study Program & yes & yes & yes & yes & yes & yes \\
\hline Observations & 799 & 785 & 784 & 784 & 775 & 769 \\
\hline R-squared & 0.11 & 0.18 & 0.22 & 0.28 & 0.41 & 0.60 \\
\hline
\end{tabular}

Robust standard errors in parentheses. ${ }^{* * *} p<0.01,{ }^{* *} p<0.05,{ }^{*} p<0.1$. Quadratic terms are demeaned. 
Table 5: Impatience and first-year academic performance

\begin{tabular}{|c|c|c|c|c|c|c|c|}
\hline \multirow{3}{*}{$\begin{array}{l}\text { Method: } \\
\text { Dependent Variable: }\end{array}$} & \multirow{2}{*}{\multicolumn{2}{|c|}{$\begin{array}{l}\text { Neg. Binomial Regression } \\
\text { Number of failed courses }\end{array}$}} & \multicolumn{2}{|c|}{ Probit } & \multirow{3}{*}{$\begin{array}{c}\text { Ols } \\
\text { Number of } \\
\text { ECTS (if <60) } \\
\text { (5) }\end{array}$} & \multicolumn{2}{|c|}{ Probit } \\
\hline & & & \multicolumn{2}{|c|}{ Obtained all ECTS } & & \multicolumn{2}{|c|}{ Received BSA } \\
\hline & $(1)$ & $(2)$ & (3) & (4) & & $(6)$ & $(7)$ \\
\hline $\begin{array}{l}\text { Always delayed or switch } \\
\text { when delayed is } € 1100\end{array}$ & & & & Reference & & & \\
\hline Switch when delayed is $€ 1250$ & $\begin{array}{c}0.041 \\
(0.112)\end{array}$ & $\begin{array}{l}-0.047 \\
(0.110)\end{array}$ & $\begin{array}{c}0.020 \\
(0.041)\end{array}$ & $\begin{array}{c}0.044 \\
(0.043)\end{array}$ & $\begin{array}{c}2.006 \\
(2.140)\end{array}$ & $\begin{array}{l}-0.036 \\
(0.027)\end{array}$ & $\begin{array}{l}-0.046^{*} \\
(0.025)\end{array}$ \\
\hline Always Immediate & $\begin{array}{c}0.420^{* * *} \\
(0.124)\end{array}$ & $\begin{array}{c}0.275^{* *} \\
(0.120)\end{array}$ & $\begin{array}{c}-0.113^{* *} \\
(0.048)\end{array}$ & $\begin{array}{l}-0.072 \\
(0.050)\end{array}$ & $\begin{array}{c}1.765 \\
(2.056)\end{array}$ & $\begin{array}{c}0.018 \\
(0.032)\end{array}$ & $\begin{array}{l}-0.006 \\
(0.028)\end{array}$ \\
\hline Score entry test Math & & $\begin{array}{c}-0.065^{* * *} \\
(0.019)\end{array}$ & & $\begin{array}{c}0.025^{* * *} \\
(0.008)\end{array}$ & $\begin{array}{l}0.587^{*} \\
(0.313)\end{array}$ & & $\begin{array}{c}-0.011^{* *} \\
(0.005)\end{array}$ \\
\hline (Score entry test Math $)^{\wedge} 2$ & & $\begin{array}{l}-0.001 \\
(0.005)\end{array}$ & & $\begin{array}{l}-0.001 \\
(0.002)\end{array}$ & $\begin{array}{c}0.089 \\
(0.076)\end{array}$ & & $\begin{array}{l}-0.001 \\
(0.001)\end{array}$ \\
\hline Score entry test Statistics & & $\begin{array}{c}-0.093^{* *} \\
(0.036)\end{array}$ & & $\begin{array}{c}0.004 \\
(0.014)\end{array}$ & $\begin{array}{c}0.607 \\
(0.649)\end{array}$ & & $\begin{array}{l}-0.005 \\
(0.009)\end{array}$ \\
\hline$(\text { Score entry test Statistics })^{\wedge} 2$ & & $\begin{array}{l}-0.018 \\
(0.019)\end{array}$ & & $\begin{array}{l}0.013^{*} \\
(0.007)\end{array}$ & $\begin{array}{c}0.553 \\
(0.355)\end{array}$ & & $\begin{array}{l}-0.009 * \\
(0.005)\end{array}$ \\
\hline Mathematics major & & $\begin{array}{l}-0.165 \\
(0.108)\end{array}$ & & $\begin{array}{c}0.041 \\
(0.043)\end{array}$ & $\begin{array}{c}2.978 \\
(1.992)\end{array}$ & & $\begin{array}{c}-0.062^{* *} \\
(0.024)\end{array}$ \\
\hline Risk attitude & & $\begin{array}{c}0.105^{* * *} \\
(0.039)\end{array}$ & & $\begin{array}{c}-0.042^{* * *} \\
(0.016)\end{array}$ & $\begin{array}{l}-0.938 \\
(0.694)\end{array}$ & & $\begin{array}{c}0.024^{* * *} \\
(0.009)\end{array}$ \\
\hline Anxiety & & $\begin{array}{c}0.159 * * * \\
(0.040)\end{array}$ & & $\begin{array}{c}-0.047^{* * *} \\
(0.015)\end{array}$ & $\begin{array}{l}-1.201 \\
(0.732)\end{array}$ & & $\begin{array}{l}0.018^{*} \\
(0.009)\end{array}$ \\
\hline Persistence & & $\begin{array}{c}0.088 \\
(0.066)\end{array}$ & & $\begin{array}{l}-0.006 \\
(0.027)\end{array}$ & $\begin{array}{l}-0.386 \\
(1.176)\end{array}$ & & $\begin{array}{c}0.006 \\
(0.016)\end{array}$ \\
\hline Self-belief & & $\begin{array}{l}-0.146^{*} \\
(0.075)\end{array}$ & & $\begin{array}{c}0.084^{* * *} \\
(0.031)\end{array}$ & $\begin{array}{c}0.259 \\
(1.232)\end{array}$ & & $\begin{array}{l}-0.023 \\
(0.018)\end{array}$ \\
\hline Gender, Age, Nationality & yes & yes & yes & yes & yes & yes & yes \\
\hline Study Program & yes & yes & yes & yes & yes & yes & yes \\
\hline Observations & 799 & 784 & 799 & 784 & 354 & 799 & 784 \\
\hline (Pseudo) R-squared & 0.01 & 0.04 & 0.04 & 0.09 & 0.11 & 0.04 & 0.10 \\
\hline
\end{tabular}


Table 6: Study efforts: time spent in electronic learning environment

Method: Quantile Regression

\begin{tabular}{|c|c|c|c|c|c|}
\hline & (1) & (2) & (3) & (4) & (5) \\
\hline \multicolumn{2}{|l|}{$\begin{array}{l}\text { Always delayed or switch when } \\
\text { delayed is } € 1100\end{array}$} & \multicolumn{3}{|c|}{ Reference } & \\
\hline \multirow[t]{2}{*}{ Switch when delayed is $€ 1250$} & $3.83^{*}$ & 2.55 & 0.09 & 2.44 & 2.67 \\
\hline & (1.98) & (1.93) & $(1.92)$ & $(1.92)$ & $(1.85)$ \\
\hline \multirow[t]{2}{*}{ Always Immediate } & 1.21 & -0.68 & -2.37 & -0.82 & -0.78 \\
\hline & $(2.27)$ & $(2.22)$ & $(2.22)$ & $(2.21)$ & (2.14) \\
\hline \multirow[t]{2}{*}{ Score entry test Math } & & -0.25 & -0.08 & -0.23 & -0.23 \\
\hline & & $(0.33)$ & $(0.33)$ & $(0.33)$ & $(0.32)$ \\
\hline \multirow[t]{2}{*}{ (Score entry test Math)^2 } & & -0.10 & -0.01 & -0.01 & 0.00 \\
\hline & & (0.09) & (0.09) & $(0.09)$ & $(0.08)$ \\
\hline \multirow{2}{*}{ Score entry test Statistics } & & $-1.69 * * *$ & $-2.03 * * *$ & $-1.78^{* * *}$ & $-1.83^{* * *}$ \\
\hline & & $(0.64)$ & $(0.64)$ & $(0.64)$ & $(0.62)$ \\
\hline \multirow{2}{*}{$($ Score entry test Statistics)^2 } & & 0.16 & $0.67^{* *}$ & $0.56^{*}$ & 0.48 \\
\hline & & $(0.31)$ & $(0.31)$ & $(0.31)$ & $(0.30)$ \\
\hline \multirow[t]{2}{*}{ Mathematics major } & & -2.80 & $-3.45^{*}$ & -1.14 & -0.65 \\
\hline & & (1.89) & (1.88) & $(1.90)$ & $(1.83)$ \\
\hline \multirow[t]{2}{*}{ Summer course } & & & & $8.35^{* * *}$ & $6.96 * * *$ \\
\hline & & & & $(2.16)$ & $(2.10)$ \\
\hline \multirow[t]{2}{*}{ Risk attitude } & & & -0.33 & -0.23 & -0.29 \\
\hline & & & $(0.69)$ & $(0.69)$ & $(0.67)$ \\
\hline \multirow[t]{2}{*}{ Anxiety } & & & $2.31^{* * *}$ & $2.43^{* * *}$ & $2.13^{* * *}$ \\
\hline & & & $(0.68)$ & $(0.68)$ & $(0.66)$ \\
\hline \multirow[t]{2}{*}{ Persistence } & & & $4.16^{* * *}$ & $3.42^{* * *}$ & $3.41 * * *$ \\
\hline & & & $(1.18)$ & $(1.18)$ & $(1.14)$ \\
\hline \multirow[t]{2}{*}{ Self-belief } & & & -1.34 & -1.58 & -1.54 \\
\hline & & & $(1.36)$ & (1.37) & $(1.32)$ \\
\hline Gender, Age, Nationality & yes & yes & yes & yes & yes \\
\hline Study Program & yes & yes & yes & yes & yes \\
\hline Observations & 798 & 785 & 784 & 784 & 767 \\
\hline Pseudo R-squared & 0.09 & 0.10 & 0.12 & 0.13 & 0.14 \\
\hline
\end{tabular}


Table 7: Study efforts: fraction of topics completed in MyLab

\begin{tabular}{|c|c|c|c|c|c|}
\hline \multirow{2}{*}{$\begin{array}{l}\text { Method: } \\
\text { Dependent variable: }\end{array}$} & \multicolumn{3}{|c|}{ Probit } & \multirow{2}{*}{$\begin{array}{c}\text { Probit } \\
\text { All topics } \\
\text { completed }\end{array}$} & \multirow{2}{*}{$\begin{array}{c}\text { OLS } \\
\begin{array}{c}\text { Fraction of topics } \\
\text { completed }\end{array}\end{array}$} \\
\hline & $\begin{array}{l}\text { Above } \\
\text { complet }\end{array}$ & $\begin{array}{l}\text { dian fractic } \\
\text { 1=above } m\end{array}$ & $\begin{array}{l}\text { f topics } \\
\text { an score) }\end{array}$ & & \\
\hline \multirow[t]{2}{*}{ Sample: } & & Full sample & & Full sample & Below median \\
\hline & $(1)$ & $(2)$ & (3) & (4) & $(5)$ \\
\hline $\begin{array}{l}\text { Always delayed or switch when } \\
\text { delayed is } € 1100\end{array}$ & \multicolumn{5}{|c|}{ Reference } \\
\hline Switch when delayed is $€ 1250$ & $\begin{array}{l}-0.026 \\
(0.043)\end{array}$ & $\begin{array}{l}-0.015 \\
(0.044)\end{array}$ & $\begin{array}{l}-0.016 \\
(0.044)\end{array}$ & $\begin{array}{c}0.026 \\
(0.028)\end{array}$ & $\begin{array}{c}0.028 \\
(0.034)\end{array}$ \\
\hline Always Immediate & $\begin{array}{l}-0.124 * * \\
(0.048)\end{array}$ & $\begin{array}{l}-0.105^{* *} \\
(0.050)\end{array}$ & $\begin{array}{l}-0.104^{* *} \\
(0.051)\end{array}$ & $\begin{array}{r}-0.028 \\
(0.031)\end{array}$ & $\begin{array}{c}0.028 \\
(0.037)\end{array}$ \\
\hline Score entry test Math & & $\begin{array}{l}0.037^{* * *} \\
(0.008)\end{array}$ & $\begin{array}{l}0.035^{* * *} \\
(0.008)\end{array}$ & $\begin{array}{c}0.021^{* * *} \\
(0.005)\end{array}$ & $\begin{array}{l}0.012 * * \\
(0.006)\end{array}$ \\
\hline (Score entry test Math)^2 & & $\begin{array}{l}-0.004^{*} \\
(0.002)\end{array}$ & $\begin{array}{l}-0.004^{* *} \\
(0.002)\end{array}$ & $\begin{array}{l}-0.003^{* *} \\
(0.001)\end{array}$ & $\begin{array}{l}-0.001 \\
(0.001)\end{array}$ \\
\hline Score entry test Statistics & & $\begin{array}{l}-0.011 \\
(0.014)\end{array}$ & $\begin{array}{l}-0.010 \\
(0.015)\end{array}$ & $\begin{array}{c}0.003 \\
(0.009)\end{array}$ & $\begin{array}{l}-0.025^{* *} \\
(0.011)\end{array}$ \\
\hline$($ Score entry test Statistics)^^2 & & $\begin{array}{c}0.001 \\
(0.007)\end{array}$ & $\begin{array}{c}0.000 \\
(0.007)\end{array}$ & $\begin{array}{r}-0.001 \\
(0.004)\end{array}$ & $\begin{array}{c}0.009 \\
(0.007)\end{array}$ \\
\hline Mathematics major & & $\begin{array}{c}0.010 \\
(0.043)\end{array}$ & $\begin{array}{r}-0.001 \\
(0.043)\end{array}$ & $\begin{array}{c}-0.002 \\
(0.026)\end{array}$ & $\begin{array}{l}-0.025 \\
(0.032)\end{array}$ \\
\hline Risk attitude & & & $\begin{array}{c}-0.053^{* * *} \\
(0.016)\end{array}$ & $\begin{array}{c}-0.043^{* * *} \\
(0.010)\end{array}$ & $\begin{array}{c}-0.024 * \\
(0.013)\end{array}$ \\
\hline Anxiety & & & $\begin{array}{c}-0.002 \\
(0.016)\end{array}$ & $\begin{array}{c}-0.030 * * * \\
(0.010)\end{array}$ & $\begin{array}{r}-0.006 \\
(0.012)\end{array}$ \\
\hline Persistence & & & $\begin{array}{c}0.039 \\
(0.027)\end{array}$ & $\begin{array}{c}0.034^{*} \\
(0.018)\end{array}$ & $\begin{array}{c}0.028 \\
(0.019)\end{array}$ \\
\hline Self-belief & & & $\begin{array}{c}0.059 * * \\
(0.030)\end{array}$ & $\begin{array}{r}-0.003 \\
(0.020)\end{array}$ & $\begin{array}{c}0.004 \\
(0.021)\end{array}$ \\
\hline Gender, Age, Nationality & yes & yes & yes & yes & yes \\
\hline Study Program & yes & yes & yes & yes & yes \\
\hline Observations & 798 & 785 & 784 & 784 & 383 \\
\hline (Pseudo)-R2 & 0.09 & 0.11 & 0.13 & 0.12 & 0.12 \\
\hline
\end{tabular}

Robust standard errors in parentheses. ${ }^{* * *} p<0.01,{ }^{* *} p<0.05, * p<0.1$. Quadratic terms are demeaned. Coefficients of probit models report mean marginal effects. 
Table 8: Study efforts: participation in summer course

Method: Probit (1=participation)

Participation in summer course

Sample: Sample:

Math major Math minor

(1)

(2)

(3)

(4)

\begin{tabular}{|c|c|c|c|c|}
\hline \multirow{2}{*}{$\begin{array}{l}\text { Always delayed or switch when } \\
\text { delayed is } € 1100 \\
\text { Switch when delayed is } € 1250\end{array}$} & \multicolumn{4}{|c|}{ Reference } \\
\hline & $\begin{array}{l}-0.010 \\
(0.032)\end{array}$ & $\begin{array}{l}-0.014 \\
(0.031)\end{array}$ & $\begin{array}{l}-0.052 \\
(0.033)\end{array}$ & $\begin{array}{c}0.013 \\
(0.044)\end{array}$ \\
\hline Always Immediate & $\begin{array}{c}0.008 \\
(0.037)\end{array}$ & $\begin{array}{c}0.004 \\
(0.036)\end{array}$ & $\begin{array}{l}-0.044 \\
(0.035)\end{array}$ & $\begin{array}{c}0.037 \\
(0.051)\end{array}$ \\
\hline Mathematics major & & $\begin{array}{c}-0.098 * * * \\
(0.027)\end{array}$ & & \\
\hline Risk attitude & & $\begin{array}{l}-0.006 \\
(0.011)\end{array}$ & $\begin{array}{c}0.007 \\
(0.015)\end{array}$ & $\begin{array}{l}-0.012 \\
(0.014)\end{array}$ \\
\hline Anxiety & & $\begin{array}{c}0.008 \\
(0.011)\end{array}$ & $\begin{array}{c}0.008 \\
(0.013)\end{array}$ & $\begin{array}{c}0.007 \\
(0.015)\end{array}$ \\
\hline Persistence & & $\begin{array}{c}0.023 \\
(0.019)\end{array}$ & $\begin{array}{c}0.034 \\
(0.024)\end{array}$ & $\begin{array}{c}0.018 \\
(0.026)\end{array}$ \\
\hline Self-belief & & $\begin{array}{c}0.074^{* * *} \\
(0.024)\end{array}$ & $\begin{array}{c}0.077^{* *} \\
(0.031)\end{array}$ & $\begin{array}{c}0.076^{* *} \\
(0.031)\end{array}$ \\
\hline Gender, Age, Nationality & yes & yes & yes & yes \\
\hline Study Program & yes & yes & yes & yes \\
\hline Observations & 799 & 792 & 271 & 521 \\
\hline Observations dep. var. $=1$ & 162 & 159 & 35 & 124 \\
\hline Observations dep. var. $=0$ & 637 & 633 & 236 & 397 \\
\hline Pseudo R2 & 0.07 & 0.11 & 0.15 & 0.09 \\
\hline
\end{tabular}


Table 9: Estimation results by ability

\begin{tabular}{|c|c|c|c|c|c|c|c|c|}
\hline \multirow[b]{2}{*}{ Dependent variable } & \multicolumn{2}{|c|}{ Results QM1 } & \multicolumn{4}{|c|}{ Results other courses } & \multicolumn{2}{|c|}{ Study Effort } \\
\hline & $\begin{array}{l}\text { Grade } \\
\text { QM1 }\end{array}$ & $\begin{array}{c}\text { Probability } \\
\text { of failing } \\
\text { exam QM1 }\end{array}$ & GPA & $\begin{array}{c}\text { Number of } \\
\text { failed } \\
\text { exams }\end{array}$ & ECTS & $\begin{array}{c}\text { probability } \\
\text { of negative } \\
\text { BSA }\end{array}$ & $\begin{array}{l}\text { Total hours } \\
\text { logged in } \\
\text { in MyLab }\end{array}$ & $\begin{array}{c}\text { Fraction } \\
\text { of topics } \\
\text { completed }\end{array}$ \\
\hline Method & $\begin{array}{l}\text { tobit } \\
(1)\end{array}$ & $\begin{array}{l}\text { probit } \\
(2)\end{array}$ & $\begin{array}{l}\text { ols } \\
\text { (3) }\end{array}$ & $\begin{array}{l}\text { neg. binomial } \\
\text { (4) }\end{array}$ & $\begin{array}{l}\text { probit } \\
\text { (5) }\end{array}$ & $\begin{array}{c}\text { probit } \\
(6)\end{array}$ & $\begin{array}{c}\text { quantile reg. } \\
\text { (7) }\end{array}$ & $\begin{array}{c}\text { probit } \\
(8)\end{array}$ \\
\hline
\end{tabular}

High ability (score on math entrytest $\geq 7$ )

\begin{tabular}{|c|c|c|c|c|c|c|c|c|}
\hline \multirow{2}{*}{$\begin{array}{l}\text { Always delayed or switch } \\
\text { when delayed is } € 1100 \\
\text { Switch when delayed is } € 1250\end{array}$} & \multicolumn{8}{|c|}{ Reference } \\
\hline & $\begin{array}{c}0.108 \\
(0.262)\end{array}$ & $\begin{array}{c}-0.047^{*} \\
(0.026)\end{array}$ & $\begin{array}{c}0.049 \\
(0.131)\end{array}$ & $\begin{array}{c}-0.053 \\
(0.174)\end{array}$ & $\begin{array}{c}0.065 \\
(0.053)\end{array}$ & $\begin{array}{c}-0.052 * * \\
(0.025)\end{array}$ & $\begin{array}{c}2.817 \\
(2.293)\end{array}$ & $\begin{array}{l}-0.000 \\
(0.057)\end{array}$ \\
\hline Always Immediate & $\begin{array}{c}-0.613^{* *} \\
(0.304)\end{array}$ & $\begin{array}{c}0.016 \\
(0.035)\end{array}$ & $\begin{array}{c}-0.348^{* *} \\
(0.159)\end{array}$ & $\begin{array}{c}0.299 \\
(0.197) \\
\end{array}$ & $\begin{array}{r}-0.038 \\
(0.067) \\
\end{array}$ & $\begin{array}{c}0.018 \\
(0.033) \\
\end{array}$ & $\begin{array}{r}-2.840 \\
(2.779) \\
\end{array}$ & $\begin{array}{l}-0.123 * \\
(0.070) \\
\end{array}$ \\
\hline Observations & 438 & 438 & 440 & 440 & 440 & 440 & 440 & 440 \\
\hline
\end{tabular}

Low ability (score on math entrytest<7)

\begin{tabular}{|c|c|c|c|c|c|c|c|c|}
\hline \multirow{2}{*}{$\begin{array}{l}\text { Always delayed or switch } \\
\text { when delayed is } € 1100 \\
\text { Switch when delayed is } € 1250\end{array}$} & \multicolumn{8}{|c|}{ Reference } \\
\hline & $\begin{array}{l}-0.414 \\
(0.268)\end{array}$ & $\begin{array}{c}0.087 \\
(0.067)\end{array}$ & $\begin{array}{l}-0.012 \\
(0.160)\end{array}$ & $\begin{array}{l}-0.038 \\
(0.142)\end{array}$ & $\begin{array}{c}0.016 \\
(0.067)\end{array}$ & $\begin{array}{l}-0.031 \\
(0.048)\end{array}$ & $\begin{array}{c}1.468 \\
(3.662)\end{array}$ & $\begin{array}{l}-0.040 \\
(0.067)\end{array}$ \\
\hline Always Immediate & $\begin{array}{c}-0.692^{* *} \\
(0.296)\end{array}$ & $\begin{array}{c}0.138 * \\
(0.074)\end{array}$ & $\begin{array}{l}-0.231 \\
(0.162) \\
\end{array}$ & $\begin{array}{c}0.231 \\
(0.149) \\
\end{array}$ & $\begin{array}{r}-0.107 \\
(0.072) \\
\end{array}$ & $\begin{array}{r}-0.027 \\
(0.052)\end{array}$ & $\begin{array}{c}1.452 \\
(3.990)\end{array}$ & $\begin{array}{l}-0.081 \\
(0.073) \\
\end{array}$ \\
\hline Observations & 340 & 340 & 344 & 344 & 344 & 344 & 344 & 344 \\
\hline
\end{tabular}

Standard errors in parentheses; ${ }^{* * *} p<0.01,{ }^{*} p<0.05, * p<0.1$. Coefficients of probit models report mean marginal effects. In all regressions, we control for age, gender, nationality, study program, tutor quality (in case of QM1), entry test scores on mathematics and statistics, demeaned entry test scores on mathematics and statistics squared, pre-education, risk attitude, anxiety, persistence, and self-belief. 
Table 10: Time spent in MyLab by level of understanding

Method: Quantile Regression

Time logged in in MyLab

\begin{tabular}{|c|c|c|c|c|}
\hline & \multicolumn{4}{|c|}{ Sample: Fraction of topics completed: } \\
\hline & $\begin{array}{l}\text { Below } \\
\text { Median }\end{array}$ & $\begin{array}{l}\text { Above } \\
\text { Median }\end{array}$ & $\begin{array}{l}\text { Below 75th } \\
\text { percentile }\end{array}$ & $\begin{array}{l}\text { Above } 75 \text { th } \\
\text { percentile }\end{array}$ \\
\hline & $(1)$ & $(2)$ & (3) & (4) \\
\hline $\begin{array}{l}\text { Always delayed or switch when } \\
\text { delayed is } € 1100\end{array}$ & & & & \\
\hline Switch when delayed is $€ 1250$ & $\begin{array}{c}3.99 \\
(3.31)\end{array}$ & $\begin{array}{c}0.06 \\
(2.28)\end{array}$ & $\begin{array}{c}3.67 \\
(2.52)\end{array}$ & $\begin{array}{l}-2.95 \\
(3.67)\end{array}$ \\
\hline Always Immediate & $\begin{array}{c}0.38 \\
(3.60)\end{array}$ & $\begin{array}{l}-0.77 \\
(2.85)\end{array}$ & $\begin{array}{l}-1.92 \\
(2.84)\end{array}$ & $\begin{array}{l}-3.42 \\
(4.62)\end{array}$ \\
\hline Score entry test Math & $\begin{array}{l}-0.29 \\
(0.56)\end{array}$ & $\begin{array}{l}-0.48 \\
(0.42)\end{array}$ & $\begin{array}{l}-0.78 * \\
(0.43)\end{array}$ & $\begin{array}{l}-0.01 \\
(0.70)\end{array}$ \\
\hline (Score entry test Math)^2 & $\begin{array}{l}-0.07 \\
(0.14)\end{array}$ & $\begin{array}{l}-0.08 \\
(0.12)\end{array}$ & $\begin{array}{l}-0.08 \\
(0.11)\end{array}$ & $\begin{array}{l}-0.19 \\
(0.19)\end{array}$ \\
\hline Score entry test Statistics & $\begin{array}{c}-2.82 * * \\
(1.13)\end{array}$ & $\begin{array}{l}-0.82 \\
(0.76)\end{array}$ & $\begin{array}{c}-2.19 * * * \\
(0.84)\end{array}$ & $\begin{array}{l}-0.25 \\
(1.27)\end{array}$ \\
\hline$($ Score entry test Statistics)^ 2 & $\begin{array}{c}0.85 \\
(0.53)\end{array}$ & $\begin{array}{c}0.34 \\
(0.38)\end{array}$ & $\begin{array}{c}0.31 \\
(0.42)\end{array}$ & $\begin{array}{c}0.35 \\
(0.58)\end{array}$ \\
\hline Mathematics major & $\begin{array}{l}-5.02 \\
(3.24)\end{array}$ & $\begin{array}{l}-1.99 \\
(2.23)\end{array}$ & $\begin{array}{l}-2.94 \\
(2.50)\end{array}$ & $\begin{array}{l}-2.78 \\
(3.64)\end{array}$ \\
\hline Risk attitude & $\begin{array}{l}-1.49 \\
(1.20)\end{array}$ & $\begin{array}{l}1.51 * \\
(0.81)\end{array}$ & $\begin{array}{l}-0.38 \\
(0.93)\end{array}$ & $\begin{array}{c}1.65 \\
(1.31)\end{array}$ \\
\hline Anxiety & $\begin{array}{c}0.95 \\
(1.17)\end{array}$ & $\begin{array}{c}3.28 * * * \\
(0.81)\end{array}$ & $\begin{array}{c}2.01^{* *} \\
(0.93)\end{array}$ & $\begin{array}{c}3.59 * * * \\
(1.22)\end{array}$ \\
\hline Persistence & $\begin{array}{l}3.36 * \\
(1.89)\end{array}$ & $\begin{array}{l}2.55^{*} \\
(1.52)\end{array}$ & $\begin{array}{c}4.56^{* * *} \\
(1.50)\end{array}$ & $\begin{array}{c}2.34 \\
(2.65)\end{array}$ \\
\hline Self-belief & $\begin{array}{l}-0.72 \\
(2.08)\end{array}$ & $\begin{array}{l}-3.54^{*} \\
(1.83)\end{array}$ & $\begin{array}{l}-1.47 \\
(1.70)\end{array}$ & $\begin{array}{l}-6.00 * \\
(3.05)\end{array}$ \\
\hline Gender, Age, Nationality & yes & yes & yes & yes \\
\hline Study Program & yes & yes & yes & yes \\
\hline Observations & 383 & 401 & 584 & 200 \\
\hline Pseudo R-squared & 0.11 & 0.15 & 0.14 & 0.17 \\
\hline
\end{tabular}




\section{Appendix: Figures}

Figure A1: Distribution of time preferences

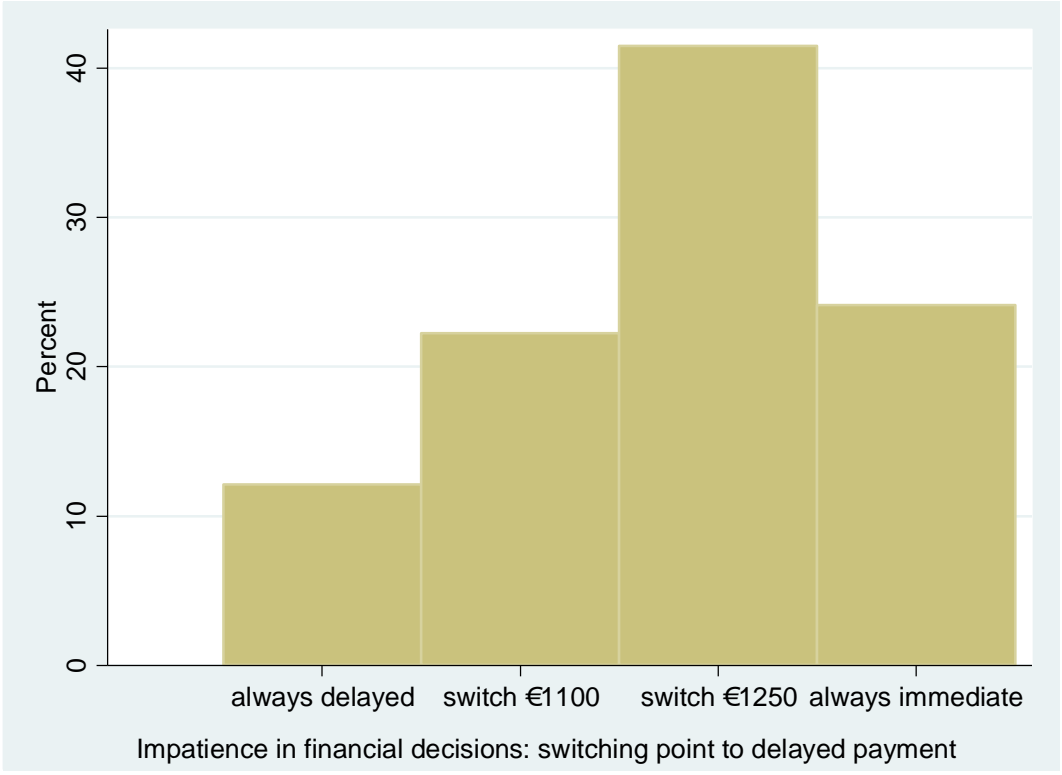

Figure A2: Distribution of entry test scores mathematics

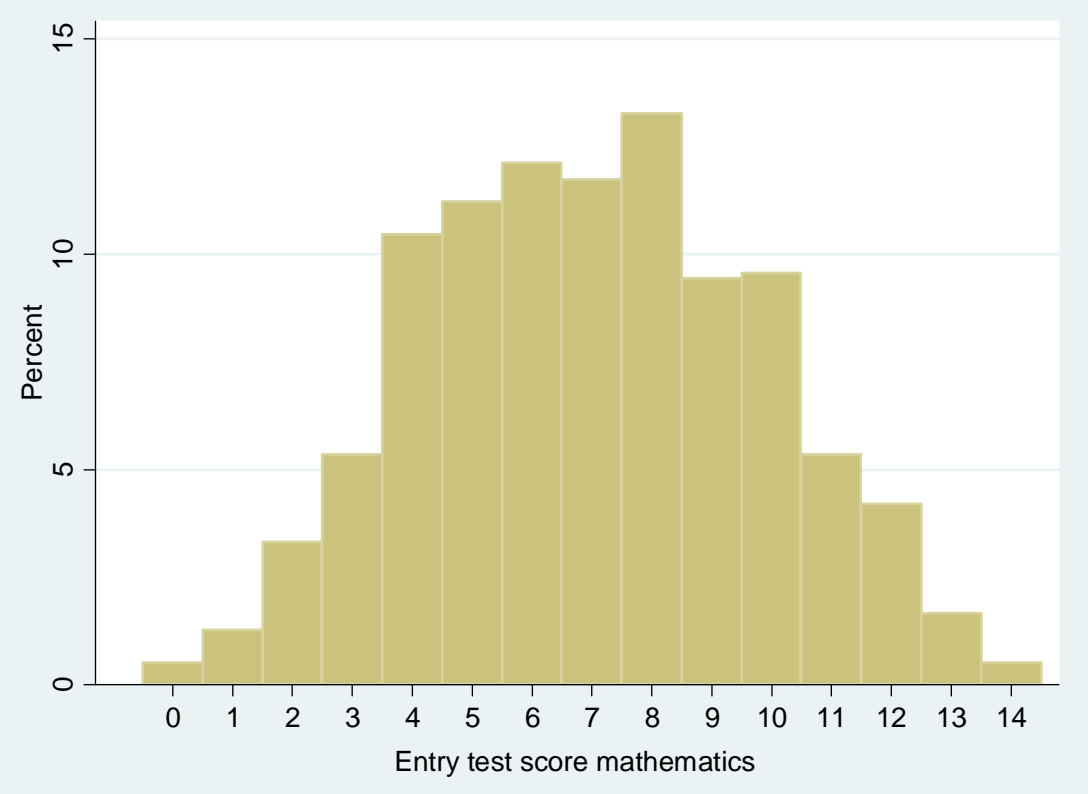


Figure A3: Distribution of grades QM1

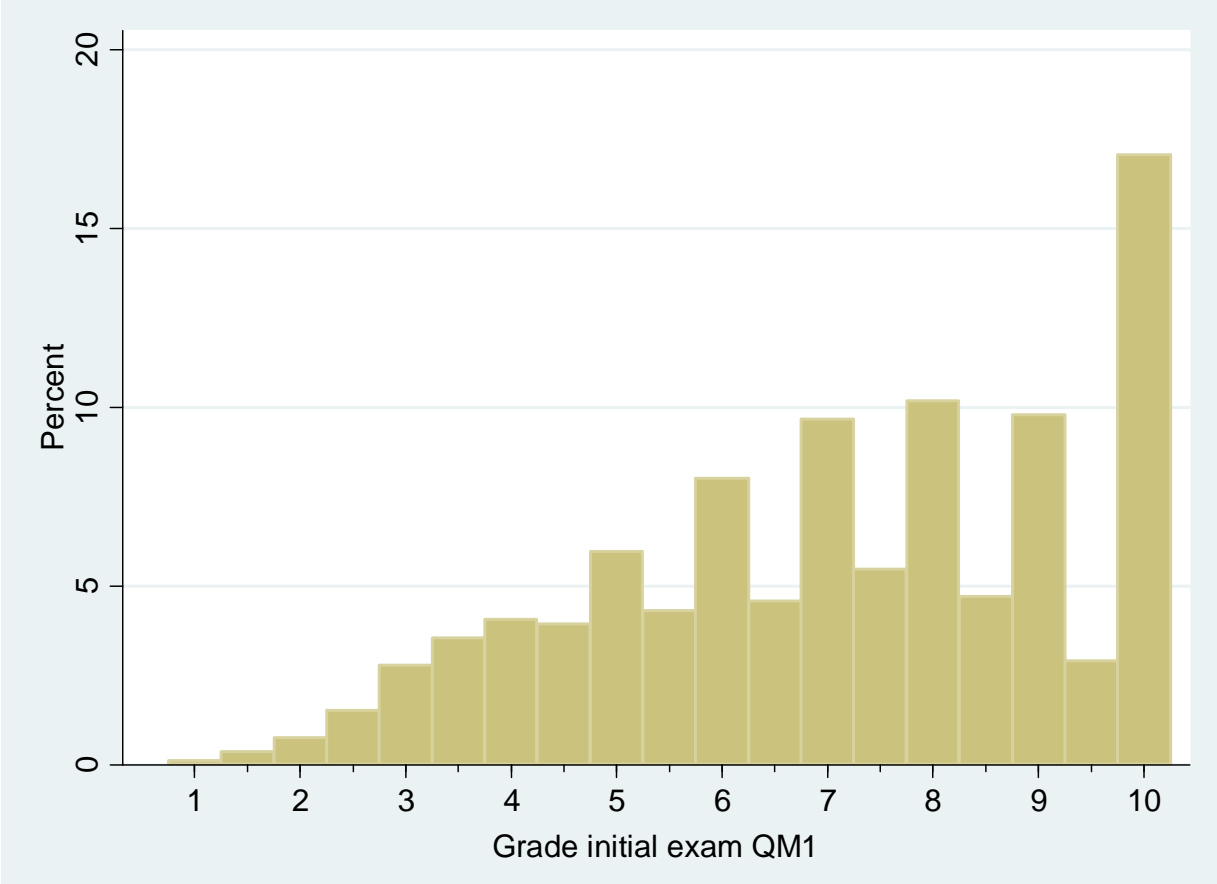

Figure A4: Distribution of GPA (excluding grade QM1)

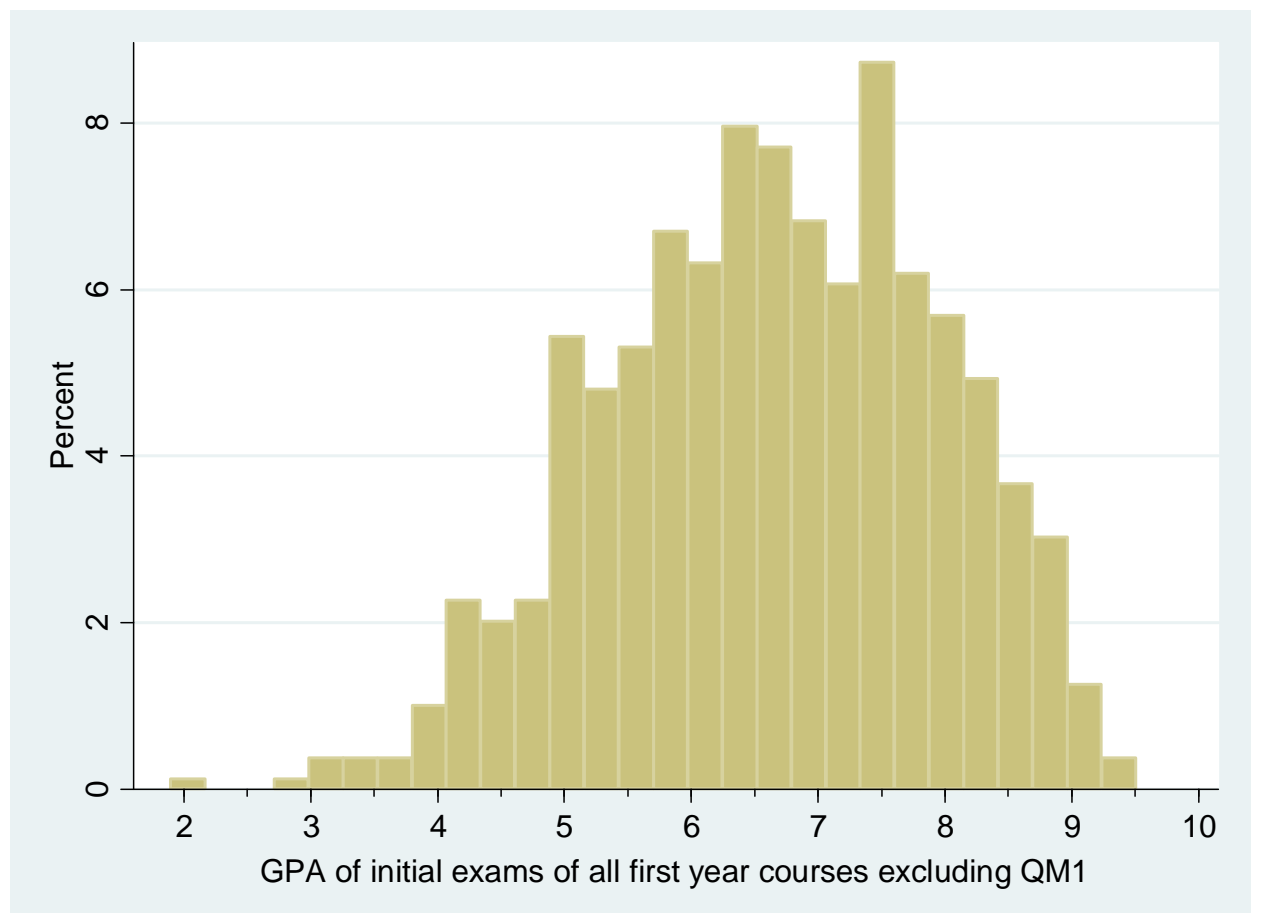


Figure A5: Distribution of the number of failed first sit exams

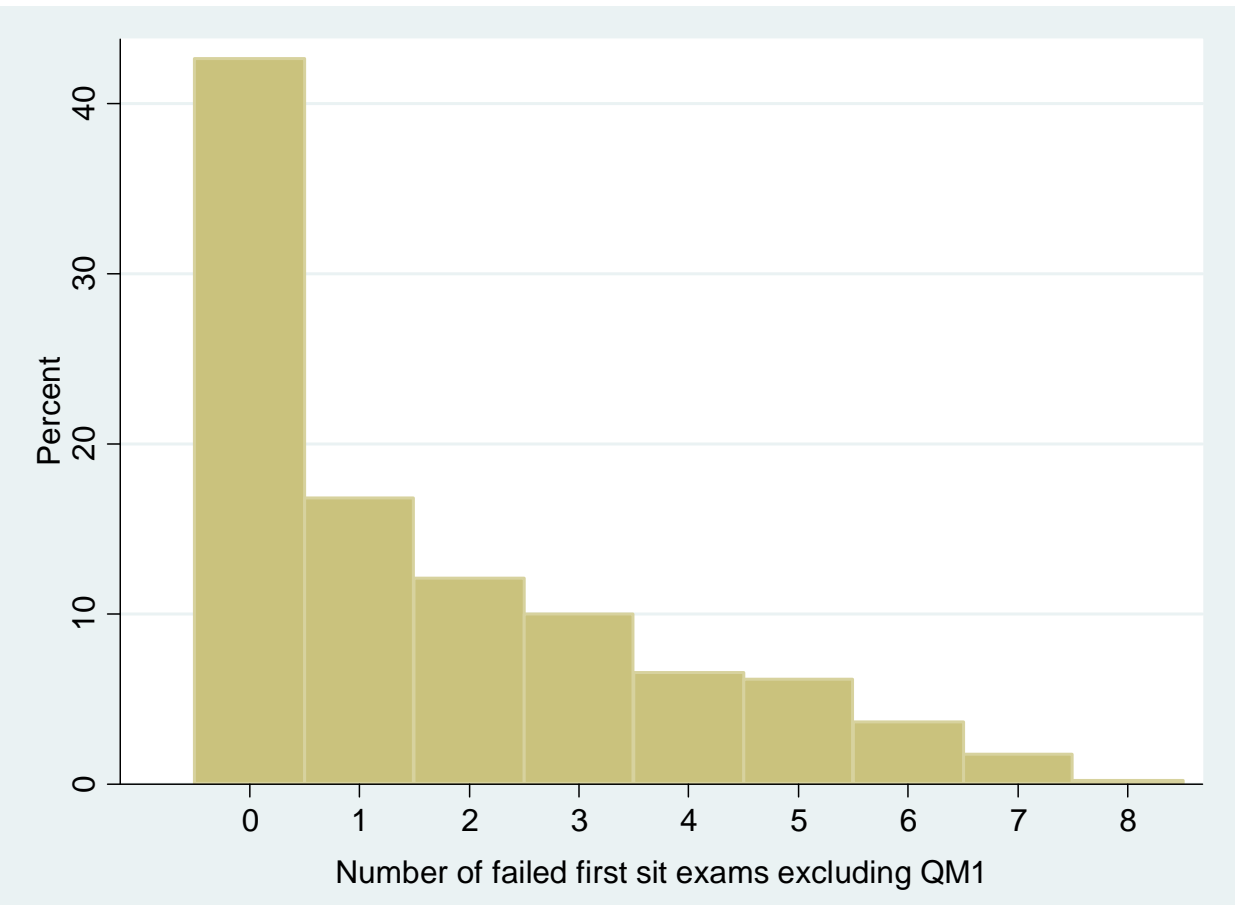

Figure A6: Distribution of the number of ECTS

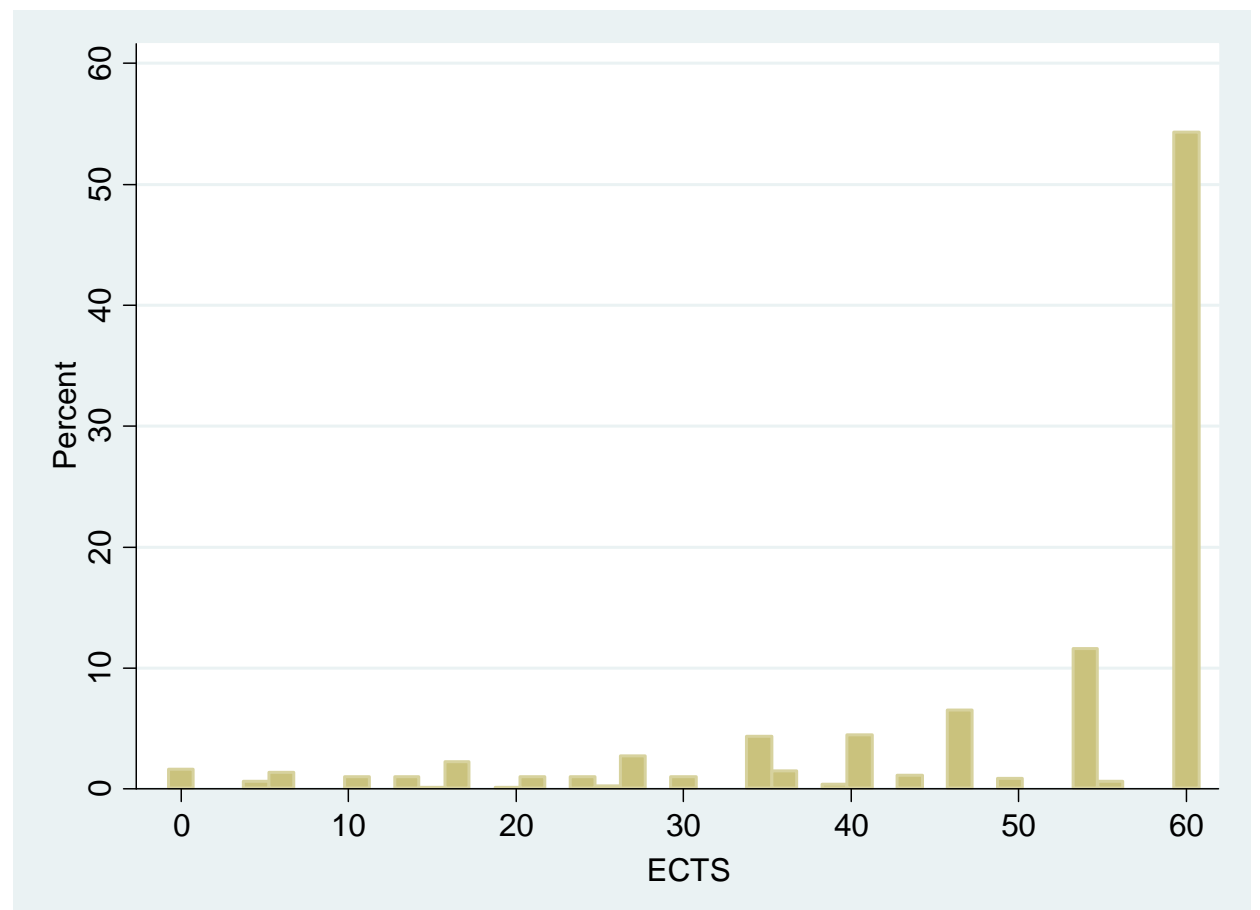


Figure A7: Distribution of time spent in MyLab

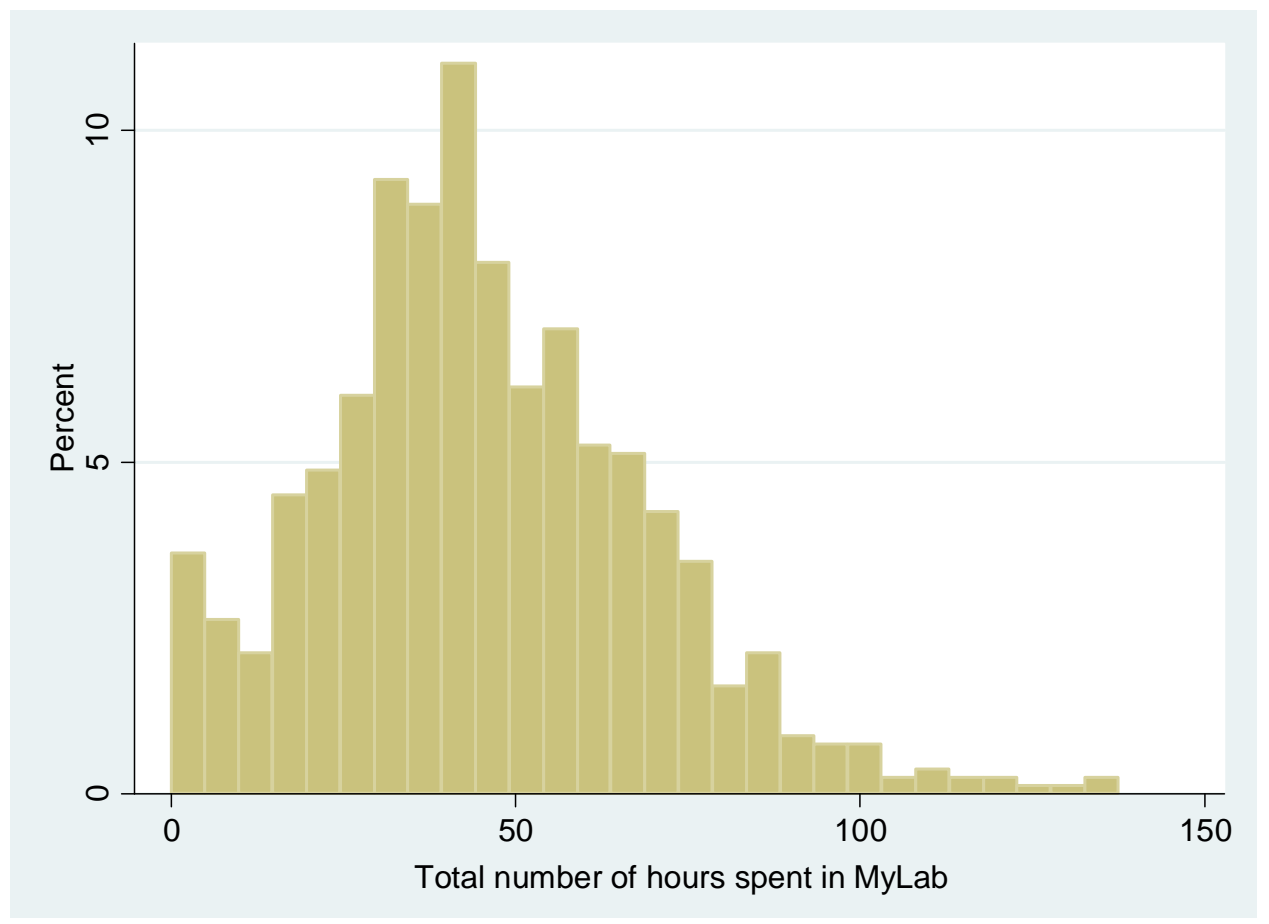

Figure A8: Distribution of fraction of topics completed

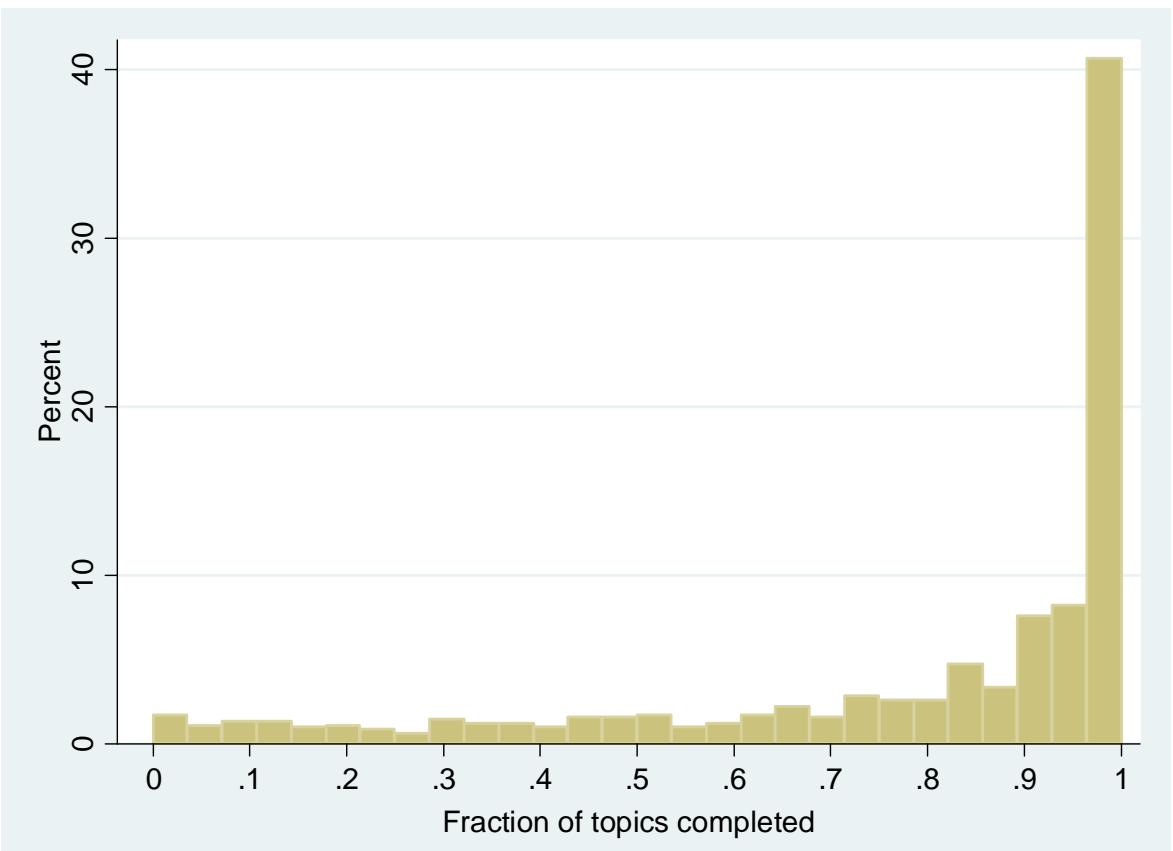

